\title{
Gas-Phase Reactions of Doubly-Charged Lanthanide Cations with Alkanes and Alkenes. Trends in Metal(2+) Reactivity
}

\author{
Joaquim Marçalo ${ }^{\mathrm{a}, *}$, Marta Santos $^{\mathrm{a}}$, António Pires de Matos ${ }^{\mathrm{a}}$, \\ John K. Gibson $^{\mathrm{b}, *}$, Richard G. Haire ${ }^{\mathrm{c}}$
}

${ }^{a}$ Departamento de Química, Instituto Tecnológico e Nuclear, 2686-953 Sacavém, Portugal

${ }^{b}$ Chemical Sciences Division, Lawrence Berkeley National Laboratory, Berkeley, CA 94720

${ }^{c}$ Chemical Sciences Division, Oak Ridge National Laboratory, Oak Ridge, TN 37831-6375

\author{
* Corresponding authors: ～(J. Marçalo) Fax: +351.21.994.6185. Email: jmarcalo@itn.pt \\ (J. K. Gibson) Fax: +1.510.486.5596. Email: jkgibson@lbl.gov
}

\begin{abstract}
The gas-phase reactivity of doubly-charged lanthanide cations, $\mathrm{Ln}^{2+}(\mathrm{Ln}=\mathrm{La}, \mathrm{Ce}, \mathrm{Pr}, \mathrm{Nd}, \mathrm{Sm}, \mathrm{Eu}, \mathrm{Gd}$, Tb, Dy, Ho, Er, Tm, Yb, Lu), with alkanes (methane, ethane, propane, n-butane) and alkenes (ethene, propene, 1-butene) was studied by Fourier transform ion cyclotron resonance mass spectrometry. The reaction products consisted of different combinations of doubly-charged organometallic ions-adducts or species formed via metal-ion-induced hydrogen, dihydrogen, alkyl, or alkane eliminations from the hydrocarbons - and singly-charged ions that resulted from electron, hydride, or methide transfers from the hydrocarbons to the metal ions. The only lanthanide cations capable of activating the hydrocarbons to form doubly-charged organometallic ions were $\mathrm{La}^{2+}, \mathrm{Ce}^{2+}, \mathrm{Gd}^{2+}$, and $\mathrm{Tb}^{2+}$, which have ground-state or low-lying $\mathrm{d}^{1}$ electronic configurations. $\mathrm{Lu}^{2+}$, with an accessible $\mathrm{d}^{1}$ electronic configuration but a rather high electron affinity, reacted only through transfer channels. The remaining $\mathrm{Ln}^{2+}$ reacted via transfer channels or adduct formation. The different accessibilities of $\mathrm{d}^{1}$ electronic configurations and the range of electron affinities of the $\mathrm{Ln}^{2+}$ cations allowed for a detailed analysis of the trends for metal $(2+)$ reactivity and the conditions for occurrence of bond activation, adduct formation, and electron, hydride, and methide transfers.
\end{abstract}

\section{Introduction}

The gas-phase reactivity of doubly-charged d-block metal cations with hydrocarbons was examined in some detail by Freiser and co-workers 10-20 years ago [1-11], following the seminal work by Tonkyn and Weisshaar [12,13] demonstrating that these cations were not limited to electron transfer reactions with hydrocarbons. Electron transfer was the only reaction pathway expected since the second ionization energies of d-transition metals are generally higher than the first ionization energies of organic molecules. In those studies [1-13], formation of doubly-charged bond-activation products, as well as $\mathrm{H}^{-}$or $\mathrm{CH}_{3}{ }^{-}$transfer reactions, were observed along with the electron-transfer routes. 
A simple, one-dimensional potential energy curve-crossing model, derived from a Landau-Zener model, as first described by Spears et al. [14], was used successfully by the groups of Weisshaar $[12,13]$ and Freiser [1-11] to explain the observed reactivity patterns. In brief, at long range, the reactants, $\mathrm{M}^{2+}+\mathrm{RH}$, follow attractive ion-induced dipole (and eventually ion-dipole) potential energy curves, whereas the charged products of electron transfer $\left(\mathrm{M}^{+}+\mathrm{RH}^{+}\right)$, hydride transfer $\left(\mathrm{MH}^{+}+\mathrm{R}^{+}\right)$or methide transfer $\left(\mathrm{MCH}_{3}{ }^{+}+\left(\mathrm{RH}-\mathrm{CH}_{3}\right)^{+}\right)$, follow repulsive Coulombic potential energy curves. The exothermicities of these transfer reactions determine the curve-crossing points and the products observed: if the transfer reaction is not sufficiently exothermic, and consequently, the curve-crossing distance is too large, the transfer of an electron, a hydride or a methide species may not be feasible. The $\mathrm{M}^{2+}$ ions can therefore survive the crossing points, attain short distances and induce the formation of doubly-charged products. This simplified model has been used and thoroughly discussed for very diverse systems involving doubly or multiply charged ions [15-21].

Hydrocarbons, alkanes and alkenes in particular, are suitable substrates to establish correlations between the electronic configurations of the ions and the reaction products and mechanisms, as extensively demonstrated in the last two decades for (mainly singly-charged) d-block and f-block metal cations [22-28].

Freiser and co-workers studied the gas-phase reactivity with alkanes of transition-metal, dipositive ions with $\mathrm{d}^{1}\left(\mathrm{Sc}^{2+}[11], \mathrm{Y}^{2+}[11], \mathrm{La}^{2+}[8]\right), \mathrm{d}^{2}\left(\mathrm{Zr}^{2+}[7]\right)$, and $\mathrm{d}^{3}\left(\mathrm{Nb}^{2+}[1,3], \mathrm{Ta}^{2+}\right.$ [7] $)$ ground-state electronic configurations, and a broad range of electron affinities $(11.1-16.2 \mathrm{eV})$. In these experiments, the authors were able to verify that the $\mathrm{d}^{1}$ metal ions had distinct reactivities relative to the $\mathrm{d}^{2}$ and $\mathrm{d}^{3}$ metal ions in terms of the formation of doubly-charged products. These differences were interpreted through the occurrence of different reaction mechanisms, bond insertion for $\mathrm{d}^{2}$ and $\mathrm{d}^{3}$ metal ions, and hydrogen abstraction or concerted bond activation for the $\mathrm{d}^{1}$ metal ions $[8,11]$.

Previous reactivity studies of doubly-charged lanthanide cations are limited to the cited efforts of Freiser and co-workers with $\mathrm{La}^{2+}[8]$ and $\mathrm{LaFe}^{2+}[2]$. The reactions of singly-charged lanthanide cations $(\mathrm{Ln}=\mathrm{La}-\mathrm{Lu}$, except $\mathrm{Pm})$ with alkanes and alkenes have been studied previously by Schwarz and co-workers [29].

Given this background, we performed Fourier transform ion cyclotron resonance mass spectrometry (FTICR/MS) [30] studies of the gas-phase reactions of doubly-charged lanthanide cations, $\mathrm{Ln}^{2+}(\mathrm{Ln}=$ $\mathrm{La}, \mathrm{Ce}, \mathrm{Pr}, \mathrm{Nd}, \mathrm{Sm}, \mathrm{Eu}, \mathrm{Gd}, \mathrm{Tb}, \mathrm{Dy}, \mathrm{Ho}, \mathrm{Er}, \mathrm{Tm}, \mathrm{Yb}$, and Lu; that is, all the lanthanides except Pm), with a few selected alkanes and alkenes. The $\mathrm{Ln}^{2+}$ ions possess "inert" $4 \mathrm{f}$ electrons, having different accessibilities of $d^{1}$ electronic configurations [31], and a range of electron affinities [31] that are appropriate for detailed analyses of $\mathrm{M}^{2+}$ reactivities. To the best of our knowledge, this is the first report of a complete, systematic study of the gas-phase reactivity of $\mathrm{Ln}^{2+}$ ions across the lanthanide series. 


\section{Experimental}

The experiments were performed in a Extrel/Finnigan FT/MS 2001-DT FTICR mass spectrometer, equipped with a 3 Tesla superconducting magnet, interfaced with a Spectra-Physics Quanta-Ray GCR$11 \mathrm{Nd}$ :YAG laser operated at the fundamental wavelength $(1064 \mathrm{~nm})$, and controlled by a Finnigan Venus Odyssey data system.

The lanthanide samples consisted of pure metal pieces obtained commercially. The hydrocarbons, obtained from Air Liquide (>99.9\% purity), were introduced into the spectrometer as supplied, through a leak valve, to pressures of $3 \times 10^{-8}$ to $2 \times 10^{-7}$ Torr. They were checked in-situ for their purity via electron-ionization (EI) mass spectra. The neutral reagent pressures were measured with a BayardAlpert type ionization gauge and calibrated using standard reactions of methane [32] and acetone [33] ions. The gauge readings were corrected for the relative sensitivities of the different reagents according to the approach of Bartmess and Georgiadis [34].

Lanthanide doubly-charged metal cations were produced by laser desorption/ionization (LDI) of the samples mounted on the solids probe of the spectrometer. All ion manipulations and analyses were performed in the source cell of the dual-cell instrument. Isolation of the $\mathrm{Ln}^{2+}$ ions was achieved using single-frequency, frequency sweep, or SWIFT excitation [35].

The reactant ions were thermalized by collisions with argon, which was introduced into the spectrometer through pulsed valves to transient pressures of $\sim 10^{-5}$ Torr, or through a leak valve to a constant pressure between $1-5 \times 10^{-6}$ Torr. The reproducibility of the reaction kinetics and the linearity of the semilog plots of normalized reactant ion intensities versus time indicated thermalization of the reactant ions had been achieved. When there was more than one product ion, reproducible product distributions for different collisional cooling periods or collision gas pressures also indicated that effective thermalization had been achieved.

It is well known that laser-ablated metal ions are produced with excess kinetic energies and can also form electronically excited states [36,37]. For the lanthanides, the occurrence of strong spin-orbit coupling makes electronic relaxation less demanding than for d-transition metals and de-excitation of of electronic excited states formed in LDI is presumed to be a relatively facile process due to this high degree of spin-orbit coupling. Collisional and radiative cooling as performed in the present study is usually sufficient to remove excess translational energy of the ions formed by LDI. In several previous studies of the reactivity of singly-charged lanthanide ions, $\mathrm{Ln}^{+},[38]$ and of doubly-charged actinide ions, $\mathrm{An}^{2+}$, [39-42], performed under experimental conditions similar to those employed in this work, no evidence was found for the involvement of excited states in the observed chemistries. In the present work, as in previous studies using this technique, effective thermalization was established by the measured reproducible pseudo first-order kinetics.

Rate constants, $k$, were determined from the pseudo first-order decays of the relative signals of the reactant ions as a function of time at constant neutral reagent pressures. Each decay was followed until the relative intensity of the reacting dipositive ion had reached less than $10 \%$ of its initial intensity. 
Along with these absolute rate constants, and for comparative purposes, reaction efficiencies are reported as $k / k_{\mathrm{COL}}$, where the $k_{\mathrm{COL}}$ is the collisional rate constant derived from the modified variational transition-state/classical trajectory theory developed by Su and Chesnavich [43]. Collisional rate constants were calculated using experimental molecular polarizabilities and dipole moments of the hydrocarbons [44]. Due to uncertainties in the pressure measurements, we estimate uncertainties up to $\pm 50 \%$ of the absolute rate constants; however, relative uncertainties are estimated to be only $\pm 20 \%$. In the reactions where two singly-charged products were generated, the product distributions were determined using the relative abundances of the metal-containing ions. The low mass ions formed in these charge-separation reactions were identified but showed low and variable intensities, most probably due to the high kinetic energies acquired [9]. Conversely, the intensities of the high mass, metal-containing ions formed were observed to be reproducible, as these product ions have lower kinetic energies [9].

Care was taken to minimize the interference of reactions with residual water and oxygen present in the the mass spectrometer. This was accomplished by using long pumping periods after the solids probe was inserted into the high-vacuum chamber of the instrument before introducing the reagents. Base pressures in the turbomolecular-pumped spectrometer were typically $\sim 10^{-8}$ Torr. All the reported reactions were compared with those occurring under these background conditions. When the reactions with residual gases were significant, the measured reaction rates and product distributions were corrected for the presence of oxygenated products formed with the reactant metal ions.

\section{Results and discussion}

The results obtained in the study of the gas-phase reactions of doubly-charged lanthanide cations with alkanes and alkenes are summarized in Tables 1 and 2, as product distributions, reaction-rate constants $(k)$, and reaction efficiencies $\left(k / k_{\mathrm{COL}}\right)$. In Table 3 we present physical data for the hydrocarbons studied needed for the discussion of the results. In Table 4 we show the low-lying electronic configurations, the corresponding energies, and the electron affinities (EAs) of the dipositive Ln cations (i.e., the second ionization energies of the elements), which are essential for the discussion. In the subsequent sections, we examine in detail the results and perform comparative analyses of the $\mathrm{Ln}^{2+}$ ions' reactivities.

[Please place Tables 1, 2, 3, and 4 here]

The primary products formed in the reactions of the $\mathrm{Ln}^{2+}$ ions with alkanes (Table 1) and alkenes (Table 2) were highly dependent on the metal ion and consisted of combinations of doubly-charged organometallic ions-adducts or species formed via metal ion-induced hydrogen, dihydrogen, alkyl, and alkane losses from the hydrocarbons-and singly-charged ions that resulted from electron, hydride, and methide transfers from the hydrocarbons to the metal ions. The types of reactions observed are summarized in equations (1) to (10). 


$$
\begin{aligned}
\mathrm{Ln}^{2+}+\mathrm{C}_{\mathrm{m}} \mathrm{H}_{\mathrm{n}} \rightarrow \mathrm{LnC}_{\mathrm{m}} \mathrm{H}_{\mathrm{n}}^{2+} & \rightarrow \mathrm{LnC}_{\mathrm{m}} \mathrm{H}_{\mathrm{n}-1}{ }^{2+}+\mathrm{H} \\
& \rightarrow \mathrm{LnC}_{\mathrm{m}} \mathrm{H}_{\mathrm{n}-2}{ }^{2+}+\mathrm{H}_{2} \\
& \rightarrow \mathrm{LnC}_{\mathrm{m}} \mathrm{H}_{\mathrm{n}-4}{ }^{2+}+2 \mathrm{H}_{2} \\
\rightarrow & \mathrm{LnC}_{\mathrm{m}-1} \mathrm{H}_{\mathrm{n}-3}{ }^{2+}+\mathrm{CH}_{3} \\
\rightarrow & \mathrm{LnC}_{\mathrm{m}-1} \mathrm{H}_{\mathrm{n}-4}{ }^{2+}+\mathrm{CH}_{4} \\
\rightarrow & \mathrm{LnC}_{\mathrm{m}-2} \mathrm{H}_{\mathrm{n}-6}{ }^{2+}+\mathrm{C}_{2} \mathrm{H}_{6} \\
\rightarrow & \mathrm{Ln}^{+}+\mathrm{C}_{\mathrm{m}} \mathrm{H}_{\mathrm{n}}^{+} \\
\rightarrow & \mathrm{Ln}^{+}+\mathrm{C}_{\mathrm{m}-\mathrm{m}} \mathrm{H}_{\mathrm{n}-\mathrm{n}}{ }^{+}+\mathrm{C}_{\mathrm{m}}, \mathrm{H}_{\mathrm{n}}{ }^{\prime} \\
\rightarrow & \mathrm{LnH}^{+}+\mathrm{C}_{\mathrm{m}} \mathrm{H}_{\mathrm{n}-1}{ }^{+} \\
\rightarrow & \mathrm{LnCH}_{3}^{+}+\mathrm{C}_{\mathrm{m}-1} \mathrm{H}_{\mathrm{n}-3}{ }^{+}
\end{aligned}
$$

For the electron transfer (ET) reactions identified in the present work it was not possible to establish whether this was non-dissociative electron transfer (NDET) as in equation 8a, dissociative electron transfer (DET) as in equation $8 \mathrm{~b}$, or some combination of NDET and DET. With this caveat that we could not differentiate between NDET and DET, we generally refer simply to ET from the hydrocarbons to the $\mathrm{Ln}^{2+}$; furthermore, references to equation 8 implicitly include both equations $8 \mathrm{a}$ and $8 \mathrm{~b}$. In the case of the alkanes (Table 1), none of the metal cations reacted with methane. Only $\mathrm{Gd}^{2+}$ and $\mathrm{Lu}^{2+}$ were reactive with ethane: $\mathrm{Gd}$ via dehydrogenation (equation 3 ) and $\mathrm{Lu}$ via electron and hydride transfers (corresponding to equations 8 and 9, respectively). With propane and n-butane, all the $\mathrm{Ln}^{2+}$ ions were reactive by one or more of the channels represented by equations $1,3,4,6,7,8,9$, and 10. The products obtained in the reactions of $\mathrm{La}^{2+}$ with propane and n-butane, and the absence of their reactivity with methane and ethane, are in close agreement with the results obtained previously by Freiser and co-workers [8]. With ethene (Table 2), the $\mathrm{La}^{2+}$ to $\mathrm{Eu}^{2+}$ ions together with $\mathrm{Tb}^{2+}$ were unreactive; $\mathrm{Gd}^{2+}$ and the $\mathrm{Dy}^{2+}$ to $\mathrm{Yb}^{2+}$ ions reacted by electron and/or hydride transfer, corresponding to equations 8 and 9 , respectively; and $\mathrm{Lu}^{2+}$ reacted by electron transfer (equation 8 ). With the other two alkenes, propene and 1-butene, all the $\mathrm{Ln}^{2+}$ ions were reactive by one or more of the channels denoted by equations $1,2,3,5,6,8,9$, and 10 .

Considering all of the reaction products, it is apparent that there is a dominance of the transfer channels, reactions 8,9 , and 10 , which can be understood by the range of $\mathrm{EA}\left[\mathrm{Ln}^{2+}\right]$ which make these reactions sufficiently exothermic for most of the $\mathrm{Ln}^{2+}$ ions (see Tables 3 and 4); $\mathrm{Lu}^{2+}$ with its rather high EA, reacts only by transfer channels. The dominance of the transfer channels is also reflected in the reaction efficiencies, as there is a general increase of the $k / k_{\mathrm{COL}}$ for the larger alkanes or alkenes, following the trend of their decreasing ionization energies and increasing polarizabilities (see Table 3 ). The prevalence of the different reaction channels is analyzed in detail in the following sections. 


\section{Trends in reactivity-electron transfer}

In Figure 1 we present a plot of the "normalized sum" of the fractions of the $k / k_{\mathrm{COL}}$ values corresponding to electron-transfer reactions for all the hydrocarbons and of the EA $\left[\mathrm{Ln}^{2+}\right]$ for the different lanthanide cations. The parallel trend observed is a clear indication that products and reaction efficiencies via the electron-transfer channel are dictated by the $\mathrm{EA}\left[\mathrm{Ln}^{2+}\right]$ values or more precisely, by the exothermicity of the reactions: $\Delta_{\mathrm{r}} H^{\mathrm{ET}}=\mathrm{IE}\left[\mathrm{C}_{\mathrm{m}} \mathrm{H}_{\mathrm{n}}\right]-\mathrm{EA}\left[\mathrm{Ln}^{2+}\right]$. The insert in Figure 1 is a plot of the normalized sum as a function of $\mathrm{EA}\left[\mathrm{Ln}^{2+}\right]$, which confirms the aforementioned point by showing a good linear correlation between these two quantities; the underlying physical significance of this intriguing linear relationship is unknown.

[Please place Figure 1 here]

The wide ranges of EA[ $\left.\mathrm{Ln}^{2+}\right]$ and $\mathrm{IE}\left[\mathrm{C}_{\mathrm{m}} \mathrm{H}_{\mathrm{n}}\right]$ values allow us to establish a threshold for electrontransfer occurance in terms of the minimum exothermicity for efficient electron hopping from a neutral to a doubly-charged cation. In Figure 2 we present a plot of the individual fraction of the $k / k_{\mathrm{COL}}$ corresponding to electron transfer for all the $\mathrm{Ln}^{2+} /$ hydrocarbon pairs, as a function of the exothermicity, $\mathrm{IE}\left[\mathrm{C}_{\mathrm{m}} \mathrm{H}_{\mathrm{n}}\right]-\mathrm{EA}\left[\mathrm{Ln}^{2+}\right]$, for the electron-transfer reactions. From the plot, a threshold of ca. $1.5 \mathrm{eV}$ for electron transfer is estimated and that above ca. $2.5 \mathrm{eV}$ this process dominates. This analysis expands and confirms the analogous, insightful analysis in 1991 by Roth and Freiser [9]. ET from neutrals to dipositive ions has been effectively modeled using Landau-Zener theory, as described by Price [19]. According to this model there is a reaction window for which the curve-crossing between the reactants, $\mathrm{Ln}^{2+}$ and $\mathrm{C}_{\mathrm{m}} \mathrm{H}_{\mathrm{n}}$, and the products, $\mathrm{Ln}^{+}$and $\mathrm{C}_{\mathrm{m}} \mathrm{H}_{\mathrm{n}}{ }^{+}$for NDET (eq. 8a) or $\mathrm{Ln}^{+}$and $\mathrm{C}_{\mathrm{m}-\mathrm{m}}, \mathrm{H}_{\mathrm{n}-\mathrm{n}}{ }^{+}$for DET (eq. 8b), occurs at an ion-neutral distance for which electron hopping is feasible. The exothermicity corresponding to this effective hopping range is rougly 2-6 eV [19]. In Figure 2, the predicted ET onset around $2 \mathrm{eV}$ is clearly evident. As the maximum ET exothermicity probed in this work was $<5 \mathrm{eV}$, the expected drop off in ET efficiency presumably occurs at higher energies than shown in Figure 2.

[Please place Figure 2 here]

\section{Trends in reactivity-hydride and methide transfers}

The enthalpy for the hydride-transfer reaction $\left(\Delta_{\mathrm{r}} H^{\mathrm{HT}}\right)$ can be calculated through the following equation:

$\Delta_{\mathrm{r}} H^{\mathrm{HT}}=\Delta_{\mathrm{f}} H(\mathrm{H})+\Delta_{\mathrm{f}} H\left(\mathrm{C}_{\mathrm{m}} \mathrm{H}_{\mathrm{n}-1}{ }^{+}\right)-\Delta_{\mathrm{f}} H\left(\mathrm{C}_{\mathrm{m}} \mathrm{H}_{\mathrm{n}}\right)-\mathrm{EA}\left[\mathrm{Ln}^{2+}\right]-\mathrm{D}\left[\mathrm{Ln}^{+}-\mathrm{H}\right]$

The bond dissociation energy term in eq. $11, \mathrm{D}\left[\mathrm{Ln}^{+}-\mathrm{H}\right]$, is known only for the cases of $\mathrm{La}^{+}$and $\mathrm{Lu}^{+}$, $2.48 \pm 0.09$ and $2.11 \pm 0.16 \mathrm{eV}$, respectively [47]. However, if one assumes that $\mathrm{s}^{1}$ electronic configuration of the $\mathrm{Ln}^{+}$ion is the most probable for forming the single bond to hydrogen [47], it may be considered as a first approximation that $\mathrm{D}\left[\mathrm{Ln}^{+}-\mathrm{H}\right]$ is constant along the $\mathrm{Ln}$ series, excluding $\mathrm{Lu}$. 
This relies on the fact that the ground states of the $\mathrm{Ln}^{+}$ions are of the $4 \mathrm{f}^{\mathrm{n}} 6 \mathrm{~s}^{1}$ type, with the exceptions of $\mathrm{La}^{+}\left(\mathrm{a} 5 \mathrm{~d}^{2}\right.$ ground state and a $5 \mathrm{~d}^{1} 6 \mathrm{~s}^{1}$ configuration at $\left.0.24 \mathrm{eV}\right), \mathrm{Ce}^{+}\left(\mathrm{a} 4 \mathrm{f}^{1} 5 \mathrm{~d}^{2}\right.$ ground state and a $4 \mathrm{f}^{1} 5 \mathrm{~d}^{1} 6 \mathrm{~s}^{1}$ configuration at $\left.0.30 \mathrm{eV}\right), \mathrm{Gd}^{+}\left(\mathrm{a} 4 \mathrm{f}^{7} 5 \mathrm{~d}^{1} 6 \mathrm{~s}^{1}\right.$ ground state), and $\mathrm{Lu}^{+}\left(\mathrm{a} 4 \mathrm{f}^{14} 6 \mathrm{~s}^{2}\right.$ ground state and a $4 \mathrm{f}^{14} 5 \mathrm{~d}^{1} 6 \mathrm{~s}^{1}$ configuration at $1.46 \mathrm{eV}$ ) [31]. With the sole exception of $\mathrm{Lu}^{+}$, the $\mathrm{s}^{1}$ configuration is either the ground state or within $0.3 \mathrm{eV}$ of ground, so that the $\mathrm{D}\left[\mathrm{Ln}^{+}-\mathrm{H}\right]$ can be assumed to be approximately constant.

With the assumption that $\mathrm{D}\left[\mathrm{Ln}^{+}-\mathrm{H}\right] \approx \mathrm{D}\left[\mathrm{La}^{+}-\mathrm{H}\right]$ for all the $\mathrm{Ln}$ ions except for $\mathrm{Lu}, \mathrm{EA}\left[\mathrm{Ln}^{2+}\right]$ can be used as an indicator of the exothermicity for hydride transfers, as was done in the previous section for electron transfers. In Figure 3 we show a plot of the normalized sum of the fractions of the $k / k_{\mathrm{COL}}$ values corresponding to hydride transfer for all the hydrocarbons, in conjunction with the $\mathrm{EA}\left[\mathrm{Ln}^{2+}\right]$ for the different lanthanide cations. The main feature discerned from this plot is the importance of the hydride-transfer channel for the $\mathrm{Dy}^{2+}$ to $\mathrm{Yb}^{2+}$ ions, corresponding to EAs of 11.7-12.2 eV. The diminished contribution of hydride transfer for $\mathrm{Lu}^{2+}$ is attributed to its extraordinarily high EA and the dominance of ET.

[Please place Figure 3 here]

In the case of methide transfer, we can use an approach similar that employed for hydride transfer. The enthalpy of the methide-transfer reaction $\left(\Delta_{\mathrm{r}} H^{\mathrm{MT}}\right)$ can be calculated through the following equation:

$\Delta_{\mathrm{r}} H^{\mathrm{MT}}=\Delta_{\mathrm{f}} H\left(\mathrm{CH}_{3}\right)+\Delta_{\mathrm{f}} H\left(\mathrm{C}_{\mathrm{m}-1} \mathrm{H}_{\mathrm{n}-3}{ }^{+}\right)-\Delta_{\mathrm{f}} H\left(\mathrm{C}_{\mathrm{m}} \mathrm{H}_{\mathrm{n}}\right)-\mathrm{EA}\left[\mathrm{Ln}^{2+}\right]-\mathrm{D}\left[\mathrm{Ln}^{+}-\mathrm{CH}_{3}\right]$

Again, the bond dissociation energy term in eq. $12, \mathrm{D}\left[\mathrm{Ln}^{+}-\mathrm{CH}_{3}\right]$, is known only for the cases of $\mathrm{La}^{+}$ and $\mathrm{Lu}^{+}, 2.39 \pm 0.15$ and $1.97 \pm 0.21 \mathrm{eV}$, respectively [48]. With the assumption that $\mathrm{D}\left[\mathrm{Ln}^{+}-\mathrm{CH}_{3}\right]$ is approximately constant for $\mathrm{La}-\mathrm{Yb}$, we can use $\mathrm{EA}\left[\mathrm{Ln}^{2+}\right]$ as an indicator of exothermicity and plot in Figure 4 the normalized sum of the $k / k_{\mathrm{COL}}$ values that correspond to methide transfer for all the hydrocarbons, in conjunction with the $\mathrm{EA}\left[\mathrm{Ln}^{2+}\right]$ for the different lanthanide cations. The main feature apparent from this plot is the importance of the methide transfer channel for the $\mathrm{Dy}^{2+}$ to $\mathrm{Yb}^{2+}$ ions, corresponding to EAs of 11.7-12.2 eV, and this time accompanied by $\mathrm{Gd}^{2+}$, which has an EA within this range. As with hydride transfer, the methide-transfer channel for the distinctive case of $\mathrm{Lu}^{2+}$ is depressed relative to the electron transfer channel.

[Please place Figure 4 here]

A feature evident from Figure 4-and more explicitly from the corresponding results in Table 1 -is the comparative importance of methide transfer for the reactions of $\mathrm{Gd}^{2+}$ with propane and $\mathrm{n}$-butane. It is also notable that with n-butane, methide transfer is a significant channel for $\mathrm{La}^{2+}$ but not for $\mathrm{Sm}^{2+}$, as both ions have essentially the same EA (Table 4). $\mathrm{As} \mathrm{La}^{2+}$ and $\mathrm{Gd}^{2+}$ are the only $\mathrm{Ln}^{2+}$ ions with a d ground-state configuration, their particular propensities towards methide transfer suggests a mechanism enabled by their $\mathrm{d}^{1}$ configurations. An abstraction mechanism analogous to that proposed by Freiser and co-workers for the activation of propane by $\mathrm{La}^{2+}[8]$ is consistent with these results. In 
the case of $n-\mathrm{C}_{4} \mathrm{H}_{10}$, for example, a $\mathrm{Ln}^{2+}\left[\mathrm{d}^{1}\right]$ ion (e.g., $\mathrm{Ln}=\mathrm{La}$ or $\mathrm{Gd}$ ) could abstract a methide fragment to produce an intermediate complex, formally $\left\{\mathrm{H}_{3} \mathrm{C}-\mathrm{Ln}^{2+}\right\} \bullet\left\{\mathrm{C}_{3} \mathrm{H}_{7}\right\}$. This intermediate could then either abstract an $\mathrm{H}$-atom from the propyl radical and eliminate $\mathrm{CH}_{4}$ to produce $\mathrm{LnC}_{3} \mathrm{H}_{6}{ }^{2+}$ or, as found with $\mathrm{La}^{2+}$ and $\mathrm{Gd}^{2+}$, dissociate in concert with electron transfer from propyl to produce $\mathrm{LnCH}_{3}{ }^{+}$ and $\mathrm{C}_{3} \mathrm{H}_{7}^{+}$.

The availability of $\mathrm{D}\left[\mathrm{Ln}^{+}-\mathrm{H}\right]$ and $\mathrm{D}\left[\mathrm{Ln}^{+}-\mathrm{CH}_{3}\right]$ values for $\mathrm{Ln}=\mathrm{La}$ and $\mathrm{Lu}[46,47]$, together with the other thermodynamic data needed in equations 11 and 12 [31,45], allow us to calculate the enthalpies of the hydride and methide transfer reactions for a few particularly relevant cases and compare them with the enthalpies for the electron-transfer reactions $\left(\Delta_{\mathrm{r}} H^{\mathrm{ET}}\right)$ and the reactivity results.

In the case of $\mathrm{La}^{2+}$ (see Tables 1 and 2), transfer reactions do not occur with propane, where $\Delta_{\mathrm{r}} H^{\mathrm{ET}}=-$ $0.11 \mathrm{eV}, \Delta_{\mathrm{r}} H^{\mathrm{HT}}=-1.92 \mathrm{eV}$, and $\Delta_{\mathrm{r}} H^{\mathrm{MT}}=-1.51 \mathrm{eV}$. With n-butane, $\mathrm{H}^{-}$and $\mathrm{CH}_{3}{ }^{-}$transfers occur but electron transfer does not; the enthalpies are: $\Delta_{\mathrm{r}} H^{\mathrm{ET}}=-0.53 \mathrm{eV}, \Delta_{\mathrm{r}} H^{\mathrm{HT}}=-2.03 \mathrm{eV}$, and $\Delta_{\mathrm{r}} H^{\mathrm{MT}}=-2.35$ $\mathrm{eV}$. Similar calculations for propene, where transfer reactions do not occur, lead to $\Delta_{\mathrm{r}} H^{\mathrm{ET}}=-1.33 \mathrm{eV}$, $\Delta_{\mathrm{r}} H^{\mathrm{HT}}=-1.69 \mathrm{eV}$, and $\Delta_{\mathrm{r}} H^{\mathrm{MT}}=-0.62 \mathrm{eV}$, while for 1-butene, for which all three transfer reactions are observed, yield $\Delta_{\mathrm{r}} H^{\mathrm{ET}}=-1.48 \mathrm{eV}, \Delta_{\mathrm{r}} H^{\mathrm{HT}}=-2.52 \mathrm{eV}$, and $\Delta_{\mathrm{r}} H^{\mathrm{MT}}=-2.14 \mathrm{eV}$. In the case of $\mathrm{Lu}^{2+}$ and ethane, where electron and hydride transfers are observed, the enthalpies are: $\Delta_{\mathrm{r}} H^{\mathrm{ET}}=-2.38 \mathrm{eV}, \Delta_{\mathrm{r}} H^{\mathrm{HT}}$ $=-3.53 \mathrm{eV}$, and $\Delta_{\mathrm{r}} H^{\mathrm{MT}}=-2.16 \mathrm{eV}$. From these observations for $\mathrm{La}^{2+}$, it appears that the thermodynamic thresholds for the hydride- and methide-transfer reactions to occur are ca. $2 \mathrm{eV}$. These conclusions about the thresholds for transfer reactions and, simultaneously, the assumptions presented above on the constancy of the $\mathrm{D}\left[\mathrm{Ln}^{+}-\mathrm{H}\right]$ and $\mathrm{D}\left[\mathrm{Ln}^{+}-\mathrm{CH}_{3}\right]$ values along the lanthanide series, can be further evaluated if we plot, as in Figure 5, the individual $k / k_{\mathrm{COL}}$ fractions corresponding to hydride and methide transfers for all the $\mathrm{Ln}^{2+} /$ hydrocarbon pairs as functions of the respective exothermicities $\Delta_{\mathrm{r}} H^{\mathrm{HT}}$ and $\Delta_{\mathrm{r}} H^{\mathrm{MT}}$. The enthalpies of the reactions were calculated through equations 11 and 12, using the approximation that the $\mathrm{D}\left[\mathrm{Ln}^{+}-\mathrm{H}\right]$ and $\mathrm{D}\left[\mathrm{Ln}^{+}-\mathrm{CH}_{3}\right]$ for all the $\mathrm{Ln}$ except for $\mathrm{Lu}$ are similar to the dissociation energies for $\mathrm{La}^{+}-\mathrm{H}$ and $\mathrm{La}^{+}-\mathrm{CH}_{3}, 2.5$ and $2.4 \mathrm{eV}$, respectively $[47,48]$. For the organic radical cations in eqns. 11 and 12, the most stable isomers were assumed to be the products-namely, i-propyl, 2-butyl, 1-propene-3-yl and 1-butene-3-yl [45]. It is feasible that some of the actual products were not the most stable isomers due to mechanistic constraints during the transfer reactions; this would not substantially affect the overall interpretations of the results.

[Please place Figure 5 here]

From Figure 5 it is evident that the hydride and methide transfers indeed appear to have thresholds of ca. $2 \mathrm{eV}$, occuring between 2 to $4 \mathrm{eV}$ and peaking at ca. $3 \mathrm{eV}$. Contrary to electron transfer, the contributions from hydride and methide transfers disappear above the upper exothermic limits; electron transfer dominates above the ca. $3 \mathrm{eV}$ upper threshold for hydride and methide transfers. This analysis confirms and expands the previous analysis by Roth and Freiser [9], is in accord with the reaction window model derived from Landau-Zener theory [19], and additionally provides thresholds 
for the both hydride and methide transfers. Roth and Freiser [9] rationalized the diminishing efficiency of hydride transfer above ca. $4 \mathrm{eV}$, just as was seen in the present work, in the context of the reaction window model. Specifically, they stated [9] that "hydride transfer peaks at $\sim 5 \AA$, and diminishes at $\leq 4 \AA$, where charge transfer dominates." Weisshaar [13] has similarly rationalized the comparative efficiencies of electron and hydride transfers in the general context of the reaction window model, with specific reference to the differences between the quantum mechanical wave functions of an electron and a hydride ion. The results in Figure 5 suggest that the same approximate reaction window pertains to methide transfer as well as hydride transfer, which is qualitatively consistent with Weisshaar's rationale [13].

\section{Trends in reactivity-adduct formation}

The observation of the formation of adducts (eq. 1) with alkanes and alkenes as primary products for some of the $\mathrm{Ln}^{2+}$ ions at low pressures in the FTICR mass spectrometer is intriguing. The efficiencies of adduct formation are all particularly low (see Tables 1 and 2). Freiser and co-workers in their studies of the reactivity of $\mathrm{M}^{2+}$ ions with alkanes, also by FTICR/MS, did not report adducts as primary products $[1,3,7,8,11]$. However, they described several displacement reactions of alkenes by alkanes in $\mathrm{MC}_{\mathrm{m}} \mathrm{H}_{2 \mathrm{~m}}{ }^{2+}$ species [6,11], which were explained theoretically by the predominant electrostatic bonding between the $\mathrm{M}^{2+}$ ions and the neutral hydrocarbons [6,49].

In Figure 6 we show a plot of the normalized sum of the $k / k_{\mathrm{COL}}$ fractions corresponding to adduct formation for all the hydrocarbons, together with the $\mathrm{EA}\left[\mathrm{Ln}^{2+}\right]$ for the different lanthanide cations. From the Figure (and also from Tables 1 and 2) it is clear that adduct formation dominates for those $\mathrm{Ln}^{2+}$ ions, $\mathrm{Pr}^{2+}$ to $\mathrm{Eu}^{2+}$, which have the lowest EAs within the $\mathrm{Ln}$ series. These ions also have a low accessibility to $\mathrm{d}^{1}$ electron configurations (see Table 4), which renders them essentially incapable of bond activation (see next section). In a few other cases, ions with intermediate EAs, such as $\mathrm{Ho}^{2+}$, or having accessibility to fairly low-lying $\mathrm{d}^{1}$ states, such as $\mathrm{Tb}^{2+}$, also result in inefficient formation of some adducts. It appears therefore that the conditions for the observation of adducts with these hydrocarbons are an EA below ca. $11.9 \mathrm{eV}\left(\mathrm{Er}^{2+}\right)$, and accessibility of $\mathrm{d}^{1}$ states above ca. $1.1 \mathrm{eV}$ $\left(\mathrm{Tb}^{2+}\right)$; that is, $\mathrm{LnC}_{\mathrm{m}} \mathrm{H}_{\mathrm{n}}{ }^{2+}$ adducts form only when both the alternative transfer and bond-activation channels are not favorable energetically or kinetically.

[Please place Figure 6 here]

It might be assumed that the energy associated with adduct formation must be dissipated by collisions with argon. For experimental conditions typically employed in the present work, the argon pressure was such that there would be on the order of 100 ion-argon collisions per second. This corresponds to ca. $10 \mathrm{~ms}$ between these stabilizing collisions, which is seemingly a rather long timescale relative to spontaneous adduct dissociation. Systematic experiments were not performed to examine the effect of experimental paramenters, particularly the argon pressure, on the efficiencies of adduct formation relative to other reaction pathways. Accordingly, it should be emphasized that both the efficiency of 
adduct formation, and the branching between this and alternative reaction pathways may be substantially different under other experimental conditions.

\section{Trends in reactivity-bond activation}

$\mathrm{La}^{2+}, \mathrm{Ce}^{2+}, \mathrm{Gd}^{2+}$, and $\mathrm{Tb}^{2+}$ were the only $\mathrm{Ln}^{2+}$ cations capable of activating the hydrocarbons to form doubly-charged organometallic ions. As can be seen in Table 4, these are precisely the ions that, together with $\mathrm{Lu}^{2+}$, have ground-state or low-lying (within ca. $1 \mathrm{eV}$ of the ground state) $\mathrm{d}^{1}$ electronic configurations. As discussed below, Freiser and co-workers $[8,11]$ proposed mechanisms in the case of $\mathrm{La}^{2+}$ which explain the role of the $\mathrm{d}^{1}$ configuration in hydrocarbon activation. There is a close correlation between the magnitudes of the promotion energies to the $\mathrm{d}^{1}$ configuration of the $\mathrm{Ln}^{2+}$, and the promotion energies to the $\mathrm{d}^{1} \mathrm{~s}^{1}$ configuration of the corresponding $\operatorname{Ln}^{+}$[31]; this latter energy determines the efficiencies of these singly-charged ions toward hydrocarbon activation [29]. Accordingly, the four doubly-charged $\mathrm{Ln}^{2+}$ which are most effective at hydrocarbon activation directly correspond to the four singly-charged $\mathrm{Ln}^{+}-\mathrm{La}^{+}, \mathrm{Ce}^{+}, \mathrm{Gd}^{+}$and $\mathrm{Tb}^{+}$-which have previously been shown to be the most reactive with hydrocarbons [29]. The non-observation of $2+$ products for $\mathrm{Lu}^{2+}$, which has a $\mathrm{d}^{1}$ state at $0.7 \mathrm{eV}$, can be explained by its rather high electron affinity as compared with the other $\mathrm{Ln}^{2+}$ ions (see Table 4), which renders the electron-transfer channel for all the hydrocarbons except methane being highly exothermic (see Table 3). The main overall differences observed between $\mathrm{La}^{2+}$ and $\mathrm{Gd}^{2+}$, both with $\mathrm{d}^{1}$ ground states, can also be attributed to the higher EA (by ca. $1 \mathrm{eV}$ ) of $\mathrm{Gd}^{2+}$, which leads to a prevalence of the transfer channels, particularly with the alkenes which have lower IEs. Another interesting difference is the fact that $\mathrm{Gd}^{2+}$ dehydrogenates ethane to form $\mathrm{GdC}_{2} \mathrm{H}_{4}{ }^{2+}$, albeit with a rather low kinetic efficiency, while $\mathrm{La}^{2+}$ does not; although both ions have $\mathrm{d}^{1}$ ground states, $\mathrm{Gd}^{2+}$ is slightly more reactive than $\mathrm{La}^{2+}$. This difference is probably due to the smaller size and higher charge density of the $\mathrm{Gd}^{2+}$ ion, which leads to a more stable ion-neutral complex and consequently a lowering of the energy barrier for bond activation.

It is instructive to compare the type of $2+$ bond-activation products formed by $\mathrm{La}^{2+}, \mathrm{Ce}^{2+}, \mathrm{Gd}^{2+}$, and $\mathrm{Tb}^{2+}$ with the alkanes with those obtained previously by Freiser and co-workers for $\mathrm{La}^{2+}[8]$ and for the group 3 ion $\mathrm{Y}^{2+}$ [11], which has a d $\mathrm{d}^{1}$ ground state and an EA close to that of $\mathrm{Gd}^{2+}$. As indicated above, there is a close match between our results to those obtained by Freiser and co-workers for the reactions of $\mathrm{La}^{2+}[8] . \mathrm{Ce}^{2+}$ and $\mathrm{Tb}^{2+}$, although less reactive, also show similarities to the $\mathrm{La}^{2+}$ ion, and $\mathrm{Gd}^{2+}$ in particular is similar to $\mathrm{Y}^{2+}$ [11]. All these ions form products resulting only from $\mathrm{H}_{2}, \mathrm{CH}_{4}$ or $\mathrm{C}_{2} \mathrm{H}_{6}$ eliminations, which Freiser and co-workers took to be indicative of a mechanism for a radical-like $\mathrm{d}^{1}$ $\mathrm{M}^{2+}$ ion $[8,11]$. These authors proposed two possible mechanisms for this type of bond activation involving the $\mathrm{d}^{1}$ configuration of the doubly-charged metal ion $[8,11]$ : initial hydrogen abstraction to form a H-M ${ }^{2+} \cdot \mathrm{C}_{\mathrm{m}} \mathrm{H}_{\mathrm{n}-1}$ intermediate, which then eliminates dihydrogen or an alkane via a multicentered transition state; or, perhaps more likely, a concerted, electrostatic mechanism involving the formation of a multi-centered $\mathrm{M}^{2+} \cdot \mathrm{C}_{\mathrm{m}} \mathrm{H}_{\mathrm{n}}$ intermediate which directly eliminates dihydrogen or an alkane. 
With the alkenes, which have not been studied previously with $\mathrm{M}^{2+}$ ions, besides observing products resulting from $\mathrm{H}_{2}$ or $\mathrm{CH}_{4}$ eliminations, new bond-activation products corresponding to radical eliminations were also observed (equations 3 and 5): specifically, for $\mathrm{La}^{2+}$, loss of $\mathrm{H}$ with propene and 1-butene and loss of $\mathrm{CH}_{3}$ with 1-butene, and for $\mathrm{Ce}^{2+}$, loss of $\mathrm{H}$ with 1-butene. These new products may arise from the presence of relatively weak allylic C-H and $\mathrm{C}-\mathrm{CH}_{3}$ bonds in 1-butene, and C-H bonds in propene. These reaction channels would appear to be consistent with the postulated abstraction mechanism $[8,11]$. In this scenario, the postulated initial step involves formation of either a $\mathrm{H}-\mathrm{Ln}^{2+} \cdot \mathrm{C}_{\mathrm{n}} \mathrm{H}_{\mathrm{n}-1}$ intermediate, which results in H-elimination (equation 3); or a $\mathrm{H}_{3} \mathrm{C}-\mathrm{Ln}^{2+} \cdot \mathrm{C}_{\mathrm{n}-1} \mathrm{H}_{\mathrm{n}-3}$ intermediate, which results in $\mathrm{CH}_{3}$-elimination (equation 5).

From the results in Tables 1 and 2, it is apparent that for bond activation to occur the $\mathrm{Ln}^{2+}$ ions must have an accessible $\mathrm{d}^{1}$ configuration, with an upper energy threshold lying between ca. $1.1 \mathrm{eV}$ for reactive $\mathrm{Tb}^{2+}$ and ca. $1.6 \mathrm{eV}$ for unreactive $\operatorname{Pr}^{2+}$ (see Table 4). Another condition for bond activation to occur, indicated by the non-observation of bond-activation products for $\mathrm{Lu}^{2+}$, is that the $\mathrm{EA}\left[\mathrm{Ln}^{2+}\right]$ cannot be so high that transfer reactions prevail. An estimate can be made for this threshold energy based on the reactions of $\mathrm{Gd}^{2+}$ and $\mathrm{Tb}^{2+}$ with 1-butene. The non-observation of bond activation for $\mathrm{Gd}^{2+}\left(\mathrm{EA}\left[\mathrm{Gd}^{2+}\right]-\mathrm{IE}\left[1-\mathrm{C}_{4} \mathrm{H}_{8}\right] \approx 2.5 \mathrm{eV}\right)$ and the observation of bond activation with $\mathrm{Tb}^{2+}\left(\mathrm{EA}\left[\mathrm{Tb}^{2+}\right]-\right.$ $\mathrm{IE}\left[1-\mathrm{C}_{4} \mathrm{H}_{8}\right] \approx 2 \mathrm{eV}$ ) indicates a threshold between 2.0 and $2.5 \mathrm{eV}$; that is, when the exothermicity for electron transfer is above this range, this transfer channel dominates and bond activation is not observed.

The conditions necessary for bond activation can also be inferred from Figure 7, where the overall relative reactivities of the $\mathrm{Ln}^{2+}$ ions with the alkanes and alkenes in terms of bond activation and resulting production of doubly-charged organometallic ions are summarized. There, the normalized sums of the fractions of the reaction efficiencies $\left(k / k_{\mathrm{COL}}\right)$ corresponding to the bond-activation channels are correlated with a combination of the EA and the promotion energy (PE) from the ground state to the lowest-lying $\mathrm{d}^{1}$ state of the $\mathrm{Ln}^{2+}$ (from Table 4). The relative weights attributed to the EA and the PE of $1 / 4$ and $3 / 4$, respectively, were roughly optimized to obtain a correlation with the reactivity results, and these weights suggest a larger relevance of the $\mathrm{PE}$ as a condition for the observation of bond activation. This plot is intended to be qualitative and not to suggest a specific correlation. If the distinctive case of $\mathrm{Lu}^{2+}$, with its unusually high EA and resulting prevalence of transfer channels, is excluded, the extent of bond activation is essentially determined by PE alone: activation requires a $\mathrm{d}^{1}$ configuration and proceeds only below a maximum promotion energy threshold which lies somewhere between ca. $1.1 \mathrm{eV}\left(\mathrm{Tb}^{2+}\right)$ and ca. $1.6 \mathrm{eV}\left(\operatorname{Pr}^{2+}\right)$.

[Please place Figure 7 here]

\section{Conclusions}

We have profited from the different accessibilities of $\mathrm{d}^{1}$ electronic configurations and the range of electron affinities of $\mathrm{Ln}^{2+}$ cations ( $\mathrm{Ln}=\mathrm{La}, \mathrm{Ce}, \mathrm{Pr}, \mathrm{Nd}, \mathrm{Sm}, \mathrm{Eu}, \mathrm{Gd}, \mathrm{Tb}, \mathrm{Dy}, \mathrm{Ho}, \mathrm{Er}, \mathrm{Tm}, \mathrm{Yb}, \mathrm{Lu}$ ) to 
perform a detailed analysis of the trends for metal (2+) reactivity with alkanes and alkenes, and in particular the conditions for the occurrence of electron, hydride, and methide transfers, adduct formation and bond activation. We were able to establish a thermodynamic threshold of ca. $1.5 \mathrm{eV}$ for electron transfer to occur, and that with an exothermicity above ca. $2.5 \mathrm{eV}$ the process dominates; from the reaction window model [19], it is presumed that the efficiency of electron transfer diminishes at higher exothermicities than examined in the present work (e.g., $>5 \mathrm{eV}$ ). We also estimated a thermodynamic threshold of ca. $2 \mathrm{eV}$ for both hydride and methide transfers to take place. We identified the thermodynamic conditions for the formation of adduct ions and for bond activation to occur in these doubly-charged metal cations with accessible $\mathrm{d}^{1}$ electronic configurations. Our analyses confirmed and substantially elaborated on the insightful analysis presented by Roth and Freiser in their 1991 overview of the reactivity of doubly-charged transition-metal ions [9].

\section{Ackowledgments}

This work was supported by Fundação para a Ciência e a Tecnologia (FCT) and POCI 2010 (cofinanced by FEDER), under contract POCI/QUI/58222/2004; and by the Director, Office of Science, Office of Basic Energy Sciences, Division of Chemical Sciences, Geosciences and Biosciences of the U.S. Department of Energy under Contracts DE-AC05-00OR22725 formerly at ORNL, and DE-AC02-05CH11231 at LBNL. M.S. is grateful to FCT for a Ph.D. grant.

\section{References}

1. Buckner, S. W.; Freiser, B. S. J. Am. Chem. Soc. 1987, 109, 1247-1248.

2. Huang, Y.; Freiser, B. S. J. Am. Chem. Soc. 1988, 110, 4434-4435.

3. Gord, J. R.; Freiser, B. S.; Buckner, S. W. J. Chem. Phys. 1989, 91, 7530-7536.

4. Gord, J. R.; Freiser, B. S.; Buckner, S. W. J. Chem. Phys. 1991, 94, 4282-4290.

5. Gord, J. R.; Freiser, B. S.; Buckner, S. W. J. Phys. Chem. 1991, 95, 8274-8279.

6. Hill, Y. D.; Freiser, B. S.; Bauschlicher, C. W., Jr. J. Am. Chem. Soc. 1991, 113, 1507-1510.

7. Ranasinghe, Y. A.; MacMahon, T.J.; Freiser, B. S. J. Phys. Chem. 1991, 95, 7721-7726.

8. Ranasinghe, Y. A.; MacMahon, T.J.; Freiser, B. S. J. Am. Chem. Soc. 1992, 114, 9112-9118.

9. Roth, L. M.; Freiser, B. S. Mass Spectrom. Rev. 1991, 10, 303-328.

10. Freiser, B. S. Acc. Chem. Res. 1994, 27, 353-360.

11. Hill, Y. D.; Huang, Y.; Ast, T.; Freiser, B. S. Rapid Commun. Mass Spectrom. 1997, 11, 149-154.

12. Tonkyn, R.; Weisshaar, J. C. J. Am. Chem. Soc. 1986, 108, 7128-7130.

13. Weisshaar, J. C. Acc. Chem. Res. 1993, 26, 213-219.

14. Spears, K. G.; Fehsenfeld, G. C.; McFarland, M.; Ferguson, E. E. J. Chem. Phys. 1972, 56, 25622566.

15. Bohme, D. K. Int. Rev. Phys. Chem. 1994, 13, 163-185.

16. Herman, Z. Int. Rev. Phys. Chem. 1996, 15, 299-324. 
17. Schröder, D.; Schwarz, H. J. Phys. Chem. A 1999, 103, 7385-7394.

18. Stace, A. J. J. Phys. Chem. A 2002, 106, 7993-8005.

19. Price, S. D. Phys. Chem. Chem. Phys. 2003, 5, 1717-1729.

20. Price, S. D. Int. J. Mass Spectrom. 2007, 260, 1-19.

21. Roithová, J.; Schröder, D. Phys. Chem. Chem. Phys. 2007, 9, 2341-2349.

22. Eller, K.; Schwarz, H. Chem. Rev. 1991, 91, 1121-1177.

23. Schwarz, H. Angew. Chem. Int. Ed. 2003, 42, 4442-4454.

24. Armentrout, P. B. Int. J. Mass Spectrom. 2003, 227, 289-302.

25. Operti, L.; Rabezzana, R. Mass Spectrom. Rev. 2006, 25, 483-513.

26. Bohme, D. K. In The Encyclopedia of Mass Spectrometry, Vol. 4; Gross, M. L., Caprioli, R., Eds.;

Elsevier: New York, 2004, pp. 638-648.

27. Gibson, J. K. Int. J. Mass Spectrom. 2002, 214, 1-21.

28. Gibson, J. K.; Marçalo, J. Coord. Chem. Rev. 2006, 250, 776-783.

29. Cornehl, H.H.; Heinemann, C.; Schröder, D.; Schwarz, H. Organometallics 1995, 14, 992-999.

30. Marshall, A. G.; Hendrickson, C. L.; Jackson, G. S. Mass Spectrom. Rev. 1998, 17, 1-35.

31. Martin, W. C.; Zalubas, R.; Hagan, L. Atomic Energy Levels - The Rare-Earth Elements; U.S.

National Bureau of Standards (NIST): Washington, DC, 1978.

32. Bruce, J. E.; Eyler, J. R. J. Am. Soc. Mass Spectrom. 1992, 3, 727-733.

33. Lin, Y.; Ridge, D. P.; Munson, B. Org. Mass Spectrom. 1991, 26, 550-558.

34. Bartmess, J. E.; Georgiadis, R. M. Vacuum 1983, 33, 149-153.

35. Guan, S.; Marshall, A. G. Int. J. Mass Spectrom. Ion Proc. 1996, 157/158, 5-37.

36. Kang, H.; Beauchamp, J. L. J. Phys. Chem. 1985, 89, 3364-3367.

37. Ibrahim, Y.; Alsharaeh, E.; Mabrouki, R.; Momoh, P.; Xie, E.; El-Shall, M. S. J. Phys. Chem. A 2008, 112, 1112-1124.

38. Marçalo, J.; Pires de Matos, A. J. Organomet. Chem. 2002, 647, 216-224.

39. Marçalo, J.; Leal, J. P.; Pires de Matos, A.; Marshall, A. G. Organometallics 1997, 16, 4581-4588.

40. Cornehl, H. H.; Heinemann, C.; Marçalo, J.; Pires de Matos, A.; Schwarz, H. Angew. Chem. Int.

Ed. Engl. 1996, 35, 891-894.

41. Gibson, J. K.; Haire, R. G.; Santos, M.; Marçalo, J.; Pires de Matos, A. J. Phys. Chem. A 2005, 109, 2768-2781.

42. Santos, M.; Pires de Matos, A.; Marçalo, J.; Gibson, J. K.; Haire, R. G.; Tyagi, R.; Pitzer, R. M. J. Phys. Chem. A 2006, 110, 5751-5759.

43. Su, T.; Chesnavich, W. J. J. Chem. Phys. 1982, 76, 5183-5185.

44. Lide, D. R., Ed.; CRC Handbook of Chemistry and Physics, 75th ed.; CRC Press: Boca Raton, FL, 1994.

45. Lias, S. G.; Bartmess, J. E.; Liebman, J. F.; Holmes, J. L.; Levin, R. D.; Mallard, W. G. Gas-Phase Ion and Neutral Thermochemistry; American Chemical Society: Washington, DC, 1988. 
46. Brewer, L. J. Opt. Soc. Am. 1971, 61, 1666-1682.

47. Elkind, J. L.; Sunderlin, L. S.; Armentrout, P. B. J. Phys. Chem. 1989, 93, 3151-3158.

48. Sunderlin, L. S.; Armentrout, P. B. J. Am. Chem. Soc. 1989, 111, 3845-3855.

49. Bauschlicher, Jr., C. W.; Langhoff, S. R. J. Phys. Chem. 1991, 95, 2278-2282. 
Table 1. Product distributions, rate constants ${ }^{\mathrm{a}}(k)$, and efficiencies $\left(k / k_{\mathrm{COL}}\right)$ of the reactions of lanthanide dipositive cations $\left(\mathrm{Ln}^{2+}\right)$ with alkanes ${ }^{\mathrm{b}}$

\begin{tabular}{|c|c|c|c|c|c|c|c|c|c|}
\hline \multirow[t]{2}{*}{$\operatorname{Ln}^{2+}$} & \multicolumn{3}{|c|}{$\mathrm{C}_{2} \mathrm{H}_{6}$} & \multicolumn{3}{|c|}{$\mathrm{C}_{3} \mathrm{H}_{8}$} & \multicolumn{3}{|c|}{$n-C_{4} H_{10}$} \\
\hline & Products & $k$ & $k / k_{\mathrm{COL}}$ & Products & $k$ & $k / k_{\mathrm{COL}}$ & Products & $k$ & $k / k_{\mathrm{COL}}$ \\
\hline $\mathrm{La}^{2+}$ & - & - & - & $\begin{array}{l}\mathrm{LaC}_{2} \mathrm{H}_{4}{ }^{2+}(20) \\
\mathrm{LaC}_{3} \mathrm{H}_{6}{ }^{2+}(80)\end{array}$ & 0.35 & 0.14 & $\begin{array}{l}\mathrm{LaC}_{2} \mathrm{H}_{4}{ }^{2+}(20) \\
\mathrm{LaC}_{3} \mathrm{H}_{6}{ }^{2+}(15) \\
\mathrm{LaC}_{4} \mathrm{H}_{6}{ }^{2+}(15) \\
\mathrm{LaC}_{4} \mathrm{H}_{8}{ }^{2+}(30) \\
\mathrm{LaH}^{+}(5) \\
\mathrm{LaCH}_{3}{ }^{+}(15)\end{array}$ & 0.58 & 0.28 \\
\hline $\mathrm{Ce}^{2+}$ & - & - & - & $\begin{array}{l}\mathrm{CeC}_{3} \mathrm{H}_{6}{ }^{2+}(50) \\
\mathrm{CeC}_{3} \mathrm{H}_{8}{ }^{2+}(50)\end{array}$ & 0.029 & 0.014 & $\begin{array}{l}\mathrm{CeC}_{2} \mathrm{H}_{4}{ }^{2+}(75) \\
\mathrm{CeC}_{3} \mathrm{H}_{6}{ }^{2+}(15) \\
\mathrm{CeC}_{4} \mathrm{H}_{8}{ }^{2+}(10)\end{array}$ & 0.37 & 0.18 \\
\hline $\operatorname{Pr}^{2+}$ & - & - & - & $\mathrm{PrC}_{3} \mathrm{H}_{8}{ }^{2+}(100)$ & 0.0023 & 0.0011 & $\mathrm{PrC}_{4} \mathrm{H}_{10}{ }^{2+}(100)$ & 0.039 & 0.019 \\
\hline $\mathrm{Nd}^{2+}$ & - & - & - & $\mathrm{NdC}_{3} \mathrm{H}_{8}{ }^{2+}(100)$ & 0.0021 & 0.0010 & $\mathrm{NdC}_{4} \mathrm{H}_{10}{ }^{2+}(100)$ & 0.067 & 0.032 \\
\hline $\mathrm{Sm}^{2+}$ & - & - & - & $\mathrm{SmC}_{3} \mathrm{H}_{8}{ }^{2+}(100)$ & 0.0020 & 0.0010 & $\begin{array}{l}\mathrm{SmC}_{4} \mathrm{H}_{10}^{2+}(95) \\
\mathrm{SmH}^{+}(5)\end{array}$ & 0.14 & 0.067 \\
\hline $\mathrm{Eu}^{2+}$ & - & - & - & $\mathrm{EuC}_{3} \mathrm{H}_{8}{ }^{2+}(100)$ & 0.0017 & 0.0009 & $\begin{array}{l}\mathrm{EuC}_{4} \mathrm{H}_{10}{ }^{2+}(90) \\
\mathrm{EuH}^{+}(10)\end{array}$ & 0.12 & 0.056 \\
\hline $\mathrm{Gd}^{2+}$ & $\mathrm{GdC}_{2} \mathrm{H}_{4}{ }^{2+}(100)$ & 0.052 & 0.027 & $\begin{array}{l}\mathrm{GdC}_{2} \mathrm{H}_{4}{ }^{2+}(25) \\
\mathrm{GdC}_{3} \mathrm{H}_{6}{ }^{2+}(10) \\
\mathrm{GdH}^{+}(20) \\
\mathrm{GdCH}_{3}{ }^{+}(45)\end{array}$ & 0.50 & 0.24 & $\begin{array}{l}\mathrm{GdC}_{2} \mathrm{H}_{4}{ }^{2+}(40) \\
\mathrm{GdC}_{3} \mathrm{H}_{6}{ }^{2+}(15) \\
\mathrm{GdC}_{4} \mathrm{H}_{8}{ }^{2+}(10) \\
\mathrm{Gd}^{+}(15) \\
\mathrm{GdH}^{+}(5) \\
\mathrm{GdCH}_{3}{ }^{+}(15)\end{array}$ & 0.53 & 0.26 \\
\hline $\mathrm{Tb}^{2+}$ & - & - & - & $\begin{array}{l}\mathrm{TbC}_{3} \mathrm{H}_{8}{ }^{2+}(30) \\
\operatorname{TbH}^{+}(70)\end{array}$ & 0.031 & 0.016 & $\begin{array}{l}\mathrm{TbC}_{2} \mathrm{H}_{4}{ }^{2+}(55) \\
\mathrm{TbC}_{3} \mathrm{H}_{6}{ }^{2+}(10) \\
\mathrm{TbH}^{+}(30) \\
\mathrm{TbCH}_{3}{ }^{+}(5)\end{array}$ & 0.39 & 0.19 \\
\hline $\mathrm{Dy}^{2+}$ & - & - & - & $\begin{array}{l}\mathrm{DyC}_{3} \mathrm{H}_{8}{ }^{2+}(5) \\
\mathrm{DyH}^{+}(95)\end{array}$ & 0.093 & 0.046 & $\begin{array}{l}\mathrm{DyH}^{+}(80) \\
\mathrm{DyCH}_{3}^{+}(20) \\
\end{array}$ & 0.47 & 0.23 \\
\hline $\mathrm{Ho}^{2+}$ & - & - & - & $\begin{array}{l}\mathrm{HoC}_{3} \mathrm{H}_{8}{ }^{2+}(5) \\
\mathrm{HoH}^{+}(95)\end{array}$ & 0.27 & 0.13 & $\begin{array}{l}\mathrm{HoH}^{+}(80) \\
\mathrm{HoCH}_{3}^{+}(20)\end{array}$ & 0.56 & 0.27 \\
\hline $\mathrm{Er}^{2+}$ & - & - & - & $\mathrm{ErH}^{+}(100)$ & 0.44 & 0.22 & $\begin{array}{l}\mathrm{ErH}^{+}(75) \\
\mathrm{ErCH}_{3}^{+}(25)\end{array}$ & 0.57 & 0.28 \\
\hline $\operatorname{Tm}^{2+}$ & - & - & - & $\begin{array}{l}\operatorname{TmH}^{+}(95) \\
\operatorname{TmCH}_{3}^{+}(5)\end{array}$ & 0.43 & 0.21 & $\begin{array}{l}\mathrm{Tm}^{+}(10) \\
\mathrm{TmH}^{+}(70) \\
\mathrm{TmCH}_{3}^{+}(20)\end{array}$ & 0.55 & 0.27 \\
\hline $\mathrm{Yb}^{2+}$ & - & - & - & $\begin{array}{l}\mathrm{YbH}^{+}(95) \\
\mathrm{YbCH}_{3}^{+}(5)\end{array}$ & 0.46 & 0.23 & $\begin{array}{l}\mathrm{Yb}^{+}(25) \\
\mathrm{YbH}^{+}(50) \\
\mathrm{YbCH}_{3}^{+}(25)\end{array}$ & 0.51 & 0.25 \\
\hline $\mathrm{Lu}^{2+}$ & $\begin{array}{l}\mathrm{Lu}^{+}(50) \\
\mathrm{LuH}^{+}(50)\end{array}$ & 0.59 & 0.30 & $\begin{array}{l}\mathrm{Lu}^{+}(75) \\
\mathrm{LuH}^{+}(10) \\
\mathrm{LuCH}_{3}^{+}(15)\end{array}$ & 0.65 & 0.33 & $\mathrm{Lu}^{+}(100)$ & 0.57 & 0.28 \\
\hline
\end{tabular}

${ }^{\mathrm{a}} k$ in units of $10^{-9} \mathrm{~cm}^{3}$ molecule ${ }^{-1} \mathrm{~s}^{-1}$

${ }^{\mathrm{b}}$ Product distributions in $\%$. A dash means that no reaction was observed $\left(k<5 \times 10^{-13} \mathrm{~cm}^{3}\right.$ molecule $\mathrm{s}^{-1} \mathrm{~s}^{-1} ; k / k_{\mathrm{COL}}$

$<0.0005)$. None of the $\mathrm{Ln}^{2+}$ reacted with $\mathrm{CH}_{4}$. 
Table 2. Product distributions, rate constants ${ }^{\mathrm{a}}(k)$, and efficiencies $\left(k / k_{\mathrm{COL}}\right)$ of the reactions of lanthanide dipositive cations $\left(\mathrm{Ln}^{2+}\right)$ with alkenes ${ }^{\mathrm{b}}$

\begin{tabular}{|c|c|c|c|c|c|c|c|c|c|}
\hline \multirow[t]{2}{*}{$\operatorname{Ln}^{2+}$} & \multicolumn{3}{|c|}{$\mathrm{C}_{2} \mathrm{H}_{4}$} & \multicolumn{3}{|c|}{$\mathrm{C}_{3} \mathrm{H}_{6}$} & \multicolumn{3}{|c|}{$1-\mathrm{C}_{4} \mathrm{H}_{8}$} \\
\hline & Products & $k$ & $k / k_{\mathrm{COL}}$ & Products & $k$ & $k / k_{\mathrm{COL}}$ & Products & $k$ & $k / k_{\mathrm{COL}}$ \\
\hline $\mathrm{La}^{2+}$ & - & - & - & $\begin{array}{l}\mathrm{LaC}_{2} \mathrm{H}_{2}{ }^{2+}(45) \\
\mathrm{LaC}_{3} \mathrm{H}_{4}{ }^{2+}(20) \\
\mathrm{LaC}_{3} \mathrm{H}_{5}{ }^{2+}(35)\end{array}$ & 0.31 & 0.14 & $\begin{array}{l}\mathrm{LaC}_{3} \mathrm{H}_{5}{ }^{2+}(40) \\
\mathrm{LaC}_{4} \mathrm{H}_{6}{ }^{2+}(15) \\
\mathrm{LaC}_{4} \mathrm{H}_{7}{ }^{2+}(5) \\
\mathrm{La}^{+}(5) \\
\mathrm{LaH}^{+}(30) \\
\mathrm{LaCH}_{3}{ }^{+}(5)\end{array}$ & 0.59 & 0.26 \\
\hline $\mathrm{Ce}^{2+}$ & - & - & - & $\mathrm{CeC}_{3} \mathrm{H}_{6}{ }^{2+}(100)$ & 0.012 & 0.0055 & $\begin{array}{l}\mathrm{CeC}_{3} \mathrm{H}_{5}^{2+}(30) \\
\mathrm{CeC}_{4} \mathrm{H}_{6}^{2+}(65) \\
\mathrm{CeH}^{+}(5)\end{array}$ & 0.38 & 0.17 \\
\hline $\mathrm{Pr}^{2+}$ & - & - & - & $\mathrm{PrC}_{3} \mathrm{H}_{6}{ }^{2+}(100)$ & 0.0021 & 0.0009 & $\begin{array}{l}\mathrm{PrC}_{4} \mathrm{H}_{8}{ }^{2+}(80) \\
\mathrm{PrH}^{+}(20)\end{array}$ & 0.092 & 0.042 \\
\hline $\mathrm{Nd}^{2+}$ & - & - & - & $\mathrm{NdC}_{3} \mathrm{H}_{6}{ }^{2+}(100)$ & 0.0026 & 0.0012 & $\begin{array}{l}\mathrm{NdC}_{4} \mathrm{H}_{8}{ }^{2+}(30) \\
\mathrm{Nd}^{+}(30) \\
\mathrm{NdH}^{+}(35) \\
\mathrm{NdCH}_{3}^{+}(5)\end{array}$ & 0.19 & 0.085 \\
\hline $\mathrm{Sm}^{2+}$ & - & - & - & $\begin{array}{l}\mathrm{SmC}_{3} \mathrm{H}_{6}{ }^{2+}(60) \\
\mathrm{Sm}^{+}(40)\end{array}$ & 0.010 & 0.0047 & $\begin{array}{l}\mathrm{Sm}^{+}(65) \\
\mathrm{SmH}^{+}(30) \\
\mathrm{SmCH}_{3}{ }^{+}(5)\end{array}$ & 0.50 & 0.23 \\
\hline $\mathrm{Eu}^{2+}$ & - & - & - & $\begin{array}{l}\mathrm{EuC}_{3} \mathrm{H}_{6}{ }^{2+}(15) \\
\mathrm{Eu}^{+}(85)\end{array}$ & 0.020 & 0.0089 & $\begin{array}{l}\mathrm{Eu}^{+}(65) \\
\mathrm{EuH}^{+}(30) \\
\mathrm{EuCH}_{3}^{+}(5)\end{array}$ & 0.58 & 0.27 \\
\hline $\mathrm{Gd}^{2+}$ & $\mathrm{Gd}^{+}(100)$ & 0.018 & 0.0093 & $\begin{array}{l}\mathrm{GdC}_{2} \mathrm{H}_{2}{ }^{2+}(10) \\
\mathrm{GdC}_{3} \mathrm{H}_{4}^{2+}(5) \\
\mathrm{Gd}^{+}(75) \\
\mathrm{GdH}^{+}(10)\end{array}$ & 0.55 & 0.25 & $\begin{array}{l}\mathrm{Gd}^{+}(95) \\
\mathrm{GdCH}_{3}^{+}(5)\end{array}$ & 0.57 & 0.26 \\
\hline $\mathrm{Tb}^{2+}$ & - & - & - & $\begin{array}{l}\mathrm{TbC}_{3} \mathrm{H}_{6}{ }^{2+}(10) \\
\mathrm{Tb}^{+}(90)\end{array}$ & 0.21 & 0.094 & $\begin{array}{l}\mathrm{TbC}_{4} \mathrm{H}_{6}{ }^{2+}(5) \\
\mathrm{Tb}^{+}(65) \\
\mathrm{TbH}^{+}(25) \\
\mathrm{TbCH}_{3}{ }^{+}(5)\end{array}$ & 0.57 & 0.26 \\
\hline $\mathrm{Dy}^{2+}$ & $\operatorname{DyH}^{+}(100)$ & 0.0011 & 0.0006 & $\mathrm{Dy}^{+}(100)$ & 0.49 & 0.22 & $\begin{array}{l}\operatorname{Dy}^{+}(80) \\
\operatorname{DyH}^{+}(15) \\
\operatorname{DyCH}_{3}^{+}(5)\end{array}$ & 0.68 & 0.32 \\
\hline $\mathrm{Ho}^{2+}$ & $\mathrm{HoH}^{+}(100)$ & 0.0017 & 0.0009 & $\mathrm{Ho}^{+}(100)$ & 0.62 & 0.28 & $\begin{array}{l}\mathrm{Ho}^{+}(80) \\
\mathrm{HoH}^{+}(15) \\
\mathrm{HoCH}_{3}^{+}(5)\end{array}$ & 0.72 & 0.33 \\
\hline $\mathrm{Er}^{2+}$ & $\begin{array}{l}\operatorname{Er}^{+}(30) \\
\operatorname{ErH}^{+}(70)\end{array}$ & 0.0024 & 0.0012 & $\operatorname{Er}^{+}(100)$ & 0.70 & 0.32 & $\begin{array}{l}\mathrm{Er}^{+}(85) \\
\operatorname{ErH}^{+}(10) \\
\mathrm{ErCH}_{3}^{+}(5) \\
\end{array}$ & 0.69 & 0.32 \\
\hline $\mathrm{Tm}^{2+}$ & $\mathrm{Tm}^{+}(100)$ & 0.015 & 0.0078 & $\mathrm{Tm}^{+}(100)$ & 0.61 & 0.28 & $\begin{array}{l}\mathrm{Tm}^{+}(85) \\
\operatorname{TmH}^{+}(10) \\
\mathrm{TmCH}_{3}{ }^{+}(5)\end{array}$ & 0.80 & 0.37 \\
\hline $\mathrm{Yb}^{2+}$ & $\mathrm{Yb}^{+}(100)$ & 0.041 & 0.021 & $\mathrm{Yb}^{+}(100)$ & 0.60 & 0.28 & $\begin{array}{l}\mathrm{Yb}^{+}(85) \\
\mathrm{YbH}^{+}(10) \\
\mathrm{YbCH}_{3}^{+}(5)\end{array}$ & 0.78 & 0.36 \\
\hline $\mathrm{Lu}^{2+}$ & $\mathrm{Lu}^{+}(100)$ & 0.64 & 0.33 & $\mathrm{Lu}^{+}(100)$ & 0.61 & 0.28 & $\mathrm{Lu}^{+}(100)$ & 0.71 & 0.33 \\
\hline
\end{tabular}

${ }^{\mathrm{a}} k$ in units of $10^{-9} \mathrm{~cm}^{3}$ molecule $\mathrm{s}^{-1} \mathrm{~s}^{-1}$

${ }^{\mathrm{b}}$ Product distributions in $\%$. A dash means that no reaction was observed $\left(k<5 \times 10^{-13} \mathrm{~cm}^{3}\right.$ molecule ${ }^{-1} \mathrm{~s}^{-1} ; k / k_{\mathrm{COL}}$ $<0.0005)$. 
Table 3. Ionization energies, polarizabilities, and dipole moments of the hydrocarbons studied ${ }^{\mathrm{a}}$

\begin{tabular}{|l|c|c|c|}
\hline $\mathbf{C}_{\mathbf{m}} \mathbf{H}_{\mathbf{n}}$ & IE $(\mathbf{e V})$ & $\alpha\left(\AA^{3}\right)$ & $\mu(\mathbf{D})$ \\
\hline $\mathrm{CH}_{4}$ & $12.51 \pm 0.01$ & 2.593 & 0 \\
$\mathrm{C}_{2} \mathrm{H}_{6}$ & $11.52 \pm 0.01$ & 4.47 & 0 \\
$\mathrm{C}_{3} \mathrm{H}_{8}$ & $10.95 \pm 0.05$ & 6.29 & 0.084 \\
$\mathrm{n}-\mathrm{C}_{4} \mathrm{H}_{10}$ & $10.53 \pm 0.10$ & 8.20 & 0 \\
\hline $\mathrm{C}_{2} \mathrm{H}_{4}$ & $10.507 \pm 0.004$ & 4.252 & 0 \\
$\mathrm{C}_{3} \mathrm{H}_{6}$ & $9.73 \pm 0.02$ & 6.26 & 0.366 \\
$1-\mathrm{C}_{4} \mathrm{H}_{8}$ & $9.58 \pm 0.02$ & 7.97 & 0.359 \\
\hline
\end{tabular}

${ }^{\text {a }}$ Ionization energies from ref. 45; polarizabilities and dipole moments from ref. 44. 
Table 4. Low-lying electronic configurations, corresponding energies, and electron affinities of dipositive lanthanide cations $\left(\mathrm{Ln}^{2+}\right)^{\mathrm{a}}$

\begin{tabular}{|c|c|c|c|}
\hline $\operatorname{Ln}^{2+}$ & $\begin{array}{c}\text { Electronic } \\
\text { configuration }\end{array}$ & Energy (eV) & $\mathrm{EA}\left[\mathbf{L n}^{2+}\right](\mathrm{eV})$ \\
\hline $\mathrm{La}^{2+}$ & $\begin{array}{l}5 \mathrm{~d}^{1} \\
4 \mathrm{f}^{1} \\
6 \mathrm{~s}^{1}\end{array}$ & $\begin{array}{c}0 \\
0.892 \\
1.685\end{array}$ & $11.06 \pm 0.01$ \\
\hline $\mathrm{Ce}^{2+}$ & $\begin{array}{c}4 \mathrm{f}^{2} \\
4 \mathrm{f}^{1} 5 \mathrm{~d}^{1} \\
4 \mathrm{f}^{1} 6 \mathrm{~s}^{1}\end{array}$ & $\begin{array}{c}0 \\
0.406 \\
2.384\end{array}$ & $10.85 \pm 0.08$ \\
\hline $\mathrm{Pr}^{2+}$ & $\begin{array}{c}4 \mathrm{f}^{3} \\
4 \mathrm{f}^{2} 5 \mathrm{~d}^{1} \\
4 \mathrm{f}^{2} 6 \mathrm{~s}^{1}\end{array}$ & $\begin{array}{c}0 \\
1.593 \\
3.521 \\
\end{array}$ & $10.55 \pm 0.08$ \\
\hline $\mathrm{Nd}^{2+}$ & $\begin{array}{c}4 \mathrm{f}^{4} \\
4 \mathrm{f}^{3} 5 \mathrm{~d}^{1} \\
4 \mathrm{f}^{3} 6 \mathrm{~s}^{1}\end{array}$ & $\begin{array}{c}0 \\
1.892 \\
3.8 \pm 0.3^{\mathrm{b}}\end{array}$ & $10.73 \pm 0.08$ \\
\hline $\mathrm{Sm}^{2+}$ & $\begin{array}{c}4 f^{6} \\
4 f^{5} 5 d^{1} \\
4 f^{5} 6 s^{1} \\
\end{array}$ & $\begin{array}{c}0 \\
3.259 \\
4.5 \pm 0.3^{\mathrm{b}}\end{array}$ & $11.07 \pm 0.08$ \\
\hline $\mathrm{Eu}^{2+}$ & $\begin{array}{c}4 f^{7} \\
4 f^{6} 5 d^{1} \\
4 f^{6} 6 s^{1}\end{array}$ & $\begin{array}{c}0 \\
4.198 \\
5.715\end{array}$ & $11.241 \pm 0.006$ \\
\hline $\mathrm{Gd}^{2+}$ & $\begin{array}{c}4 f^{7} 5 d^{1} \\
4 f^{8} \\
4 f^{7} 6 s^{1}\end{array}$ & $\begin{array}{c}0 \\
0.295 \\
1.140 \\
\end{array}$ & $12.09 \pm 0.08$ \\
\hline $\mathrm{Tb}^{2+}$ & $\begin{array}{c}4 f^{9} \\
4 f^{8} 5 d^{1} \\
4 f^{8} 6 s^{1}\end{array}$ & $\begin{array}{c}0 \\
1.112 \\
2.192 \\
\end{array}$ & $11.52 \pm 0.08$ \\
\hline $\mathrm{Dy}^{2+}$ & $\begin{array}{c}4 \mathrm{f}^{10} \\
4 \mathrm{f}^{9} 5 \mathrm{~d}^{1} \\
4 \mathrm{f}^{8} 6 \mathrm{~s}^{1}\end{array}$ & $\begin{array}{c}0 \\
2.1 \\
3.1 \pm 0.2^{\mathrm{b}}\end{array}$ & $11.67 \pm 0.08$ \\
\hline $\mathrm{Ho}^{2+}$ & $\begin{array}{c}4 \mathrm{f}^{11} \\
4 \mathrm{f}^{10} 5 \mathrm{~d}^{1} \\
4 \mathrm{f}^{10} 6 \mathrm{~s}^{1}\end{array}$ & $\begin{array}{c}0 \\
2.236 \\
2.706\end{array}$ & $11.80 \pm 0.08$ \\
\hline $\mathrm{Er}^{2+}$ & $\begin{array}{c}4 \mathrm{f}^{12} \\
4 \mathrm{f}^{11} 5 \mathrm{~d}^{1} \\
4 \mathrm{f}^{11} 6 \mathrm{~s}^{1}\end{array}$ & $\begin{array}{c}0 \\
2.104 \\
2.394 \\
\end{array}$ & $11.93 \pm 0.08$ \\
\hline $\mathrm{Tm}^{2+}$ & $\begin{array}{c}4 \mathrm{f}^{13} \\
4 \mathrm{f}^{12} 5 \mathrm{~d}^{1} \\
4 \mathrm{f}^{12} 6 \mathrm{~s}^{1}\end{array}$ & $\begin{array}{c}0 \\
2.839 \\
3.137 \\
\end{array}$ & $12.05 \pm 0.08$ \\
\hline $\mathrm{Yb}^{2+}$ & $\begin{array}{c}4 \mathrm{f}^{14} \\
4 \mathrm{f}^{13} 5 \mathrm{~d}^{1} \\
4 \mathrm{f}^{13} 6 \mathrm{~s}^{1} \\
\end{array}$ & $\begin{array}{c}0 \\
4.139 \\
4.297 \\
\end{array}$ & $12.184 \pm 0.006$ \\
\hline $\mathrm{Lu}^{2+}$ & $\begin{array}{l}4 f^{14} 6 s^{1} \\
4 f^{14} 5 d^{1}\end{array}$ & $\begin{array}{c}0 \\
0.708\end{array}$ & $13.9 \pm 0.4$ \\
\hline
\end{tabular}

${ }^{\text {a }}$ From ref. 31 except where noted; the energies correspond to the lowest levels of each configuration; $\mathrm{EA}\left[\mathrm{Ln}^{2+}\right]=\mathrm{IE}\left[\mathrm{Ln}^{+}\right]$.

${ }^{\mathrm{b}}$ Estimates from ref. 46. 


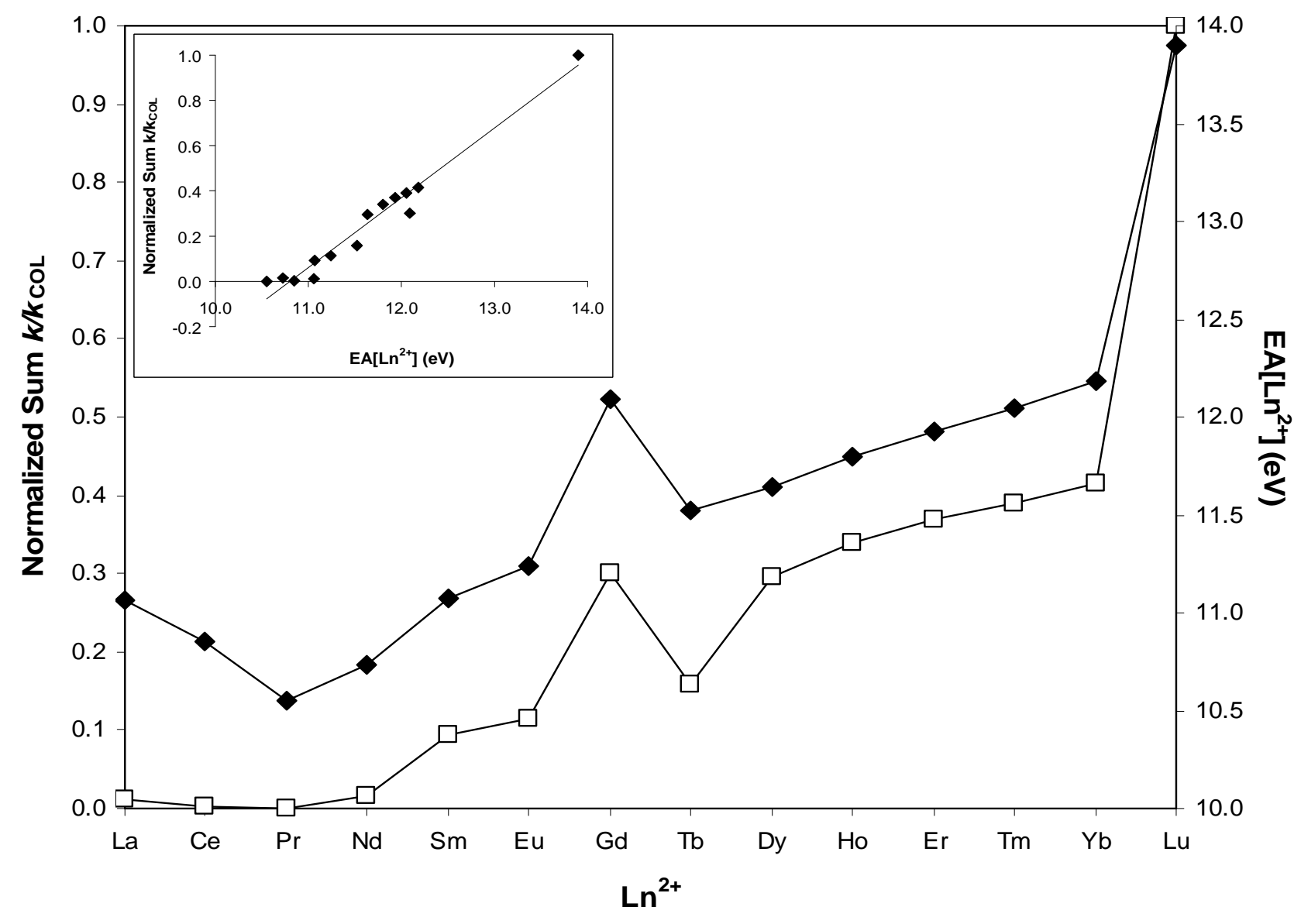

Figure 1. Plot of the normalized sum of the fraction of the $k / k_{\mathrm{COL}}$ corresponding to electron transfer (open squares) and of the EA[ $\left.\mathrm{Ln}^{2+}\right]$ (filled squares) for the different lanthanide cations; the insert is a plot of the normalized sum as a function of EA[ $\left.\mathrm{Ln}^{2+}\right]$. The "normalized sum" for a given $\mathrm{Ln}^{2+}$ is the sum of the efficiencies for electron transfer, $k^{\mathrm{ET}} / k_{\mathrm{COL}}$, for all seven $\mathrm{C}_{\mathrm{m}} \mathrm{H}_{\mathrm{n}}$, normalized to this sum for $\mathrm{Lu}^{2+}$ (which has the greatest electron-transfer efficiency). That is, $\left[k / k_{\mathrm{COL}}\right]_{\mathrm{Ln}}^{\mathrm{Norm}}=\left\{\sum\left(k^{\mathrm{ET}} / k_{\mathrm{COL}}\right)_{\mathrm{Ln}}\right\} /\left\{\sum\left(k^{\mathrm{ET}} / k_{\mathrm{COL}}\right)_{\mathrm{Lu}}\right\}$; the sum for each $\mathrm{Ln}^{2+}$ is over the seven studied $\mathrm{C}_{\mathrm{m}} \mathrm{H}_{\mathrm{n}}$ reactants. 


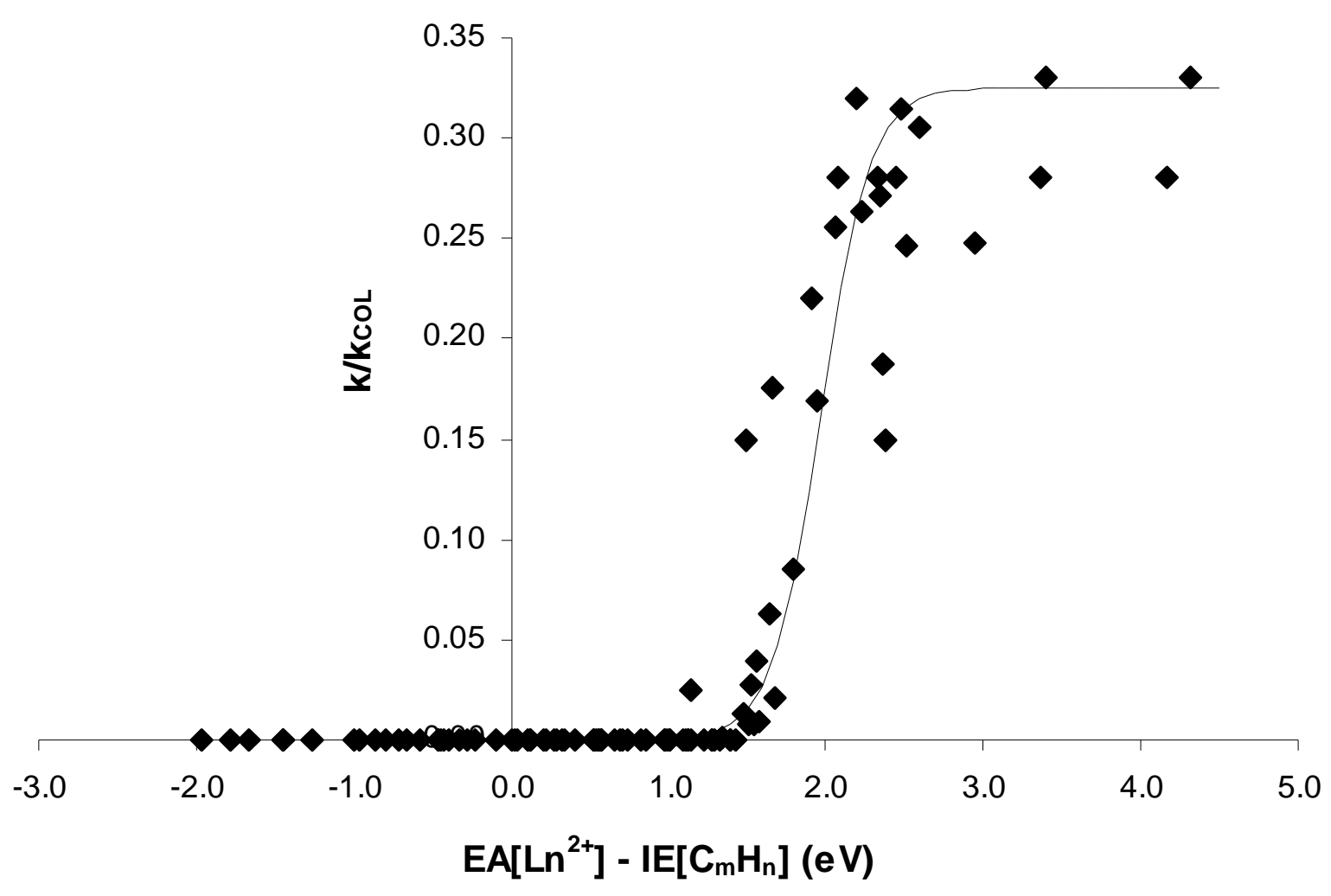

Figure 2. Plot of the individual fractions of the $k / k_{\mathrm{COL}}$ corresponding to electron transfer for all $\mathrm{Ln}^{2+} /$ hydrocarbon pairs, as a function of the exothermicity of the electron-transfer reactions $\left(-\Delta_{\mathrm{r}} H^{\mathrm{ET}}\right.$ is plotted; the sigmoid curve shown is an approximate fit to the data points). 


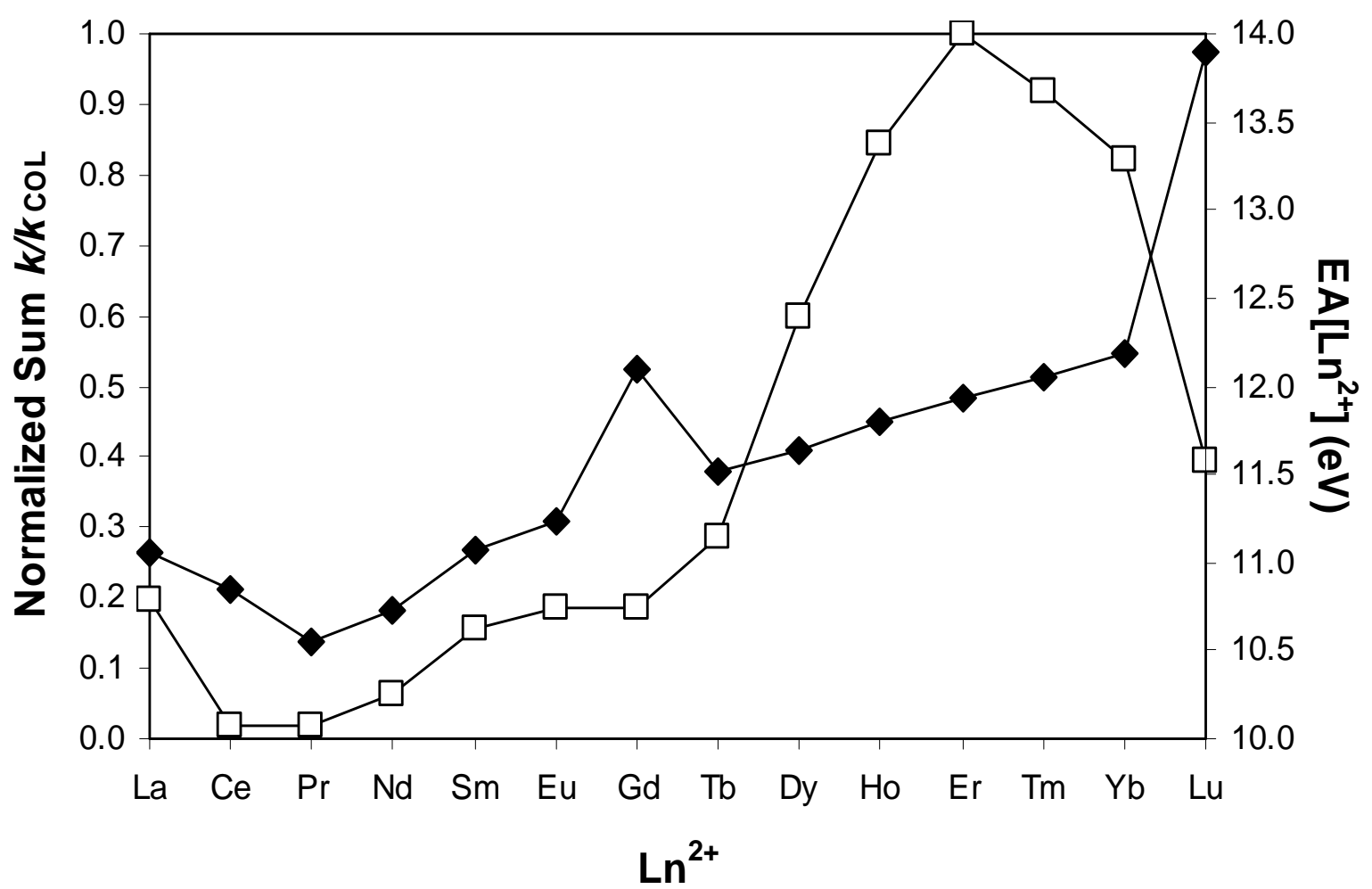

Figure 3. Plot of the normalized sum of the fraction of the $k / k_{\mathrm{COL}}$ corresponding to hydride transfer (open squares) and of the $\mathrm{EA}\left[\mathrm{Ln}^{2+}\right]$ for the different lanthanide cations (filled squares). The normalized sums are obtained in an analogous manner as for electron transfer (Figure 1); for hydride transfer the normalization is relative to $\mathrm{Er}^{2+}$. 


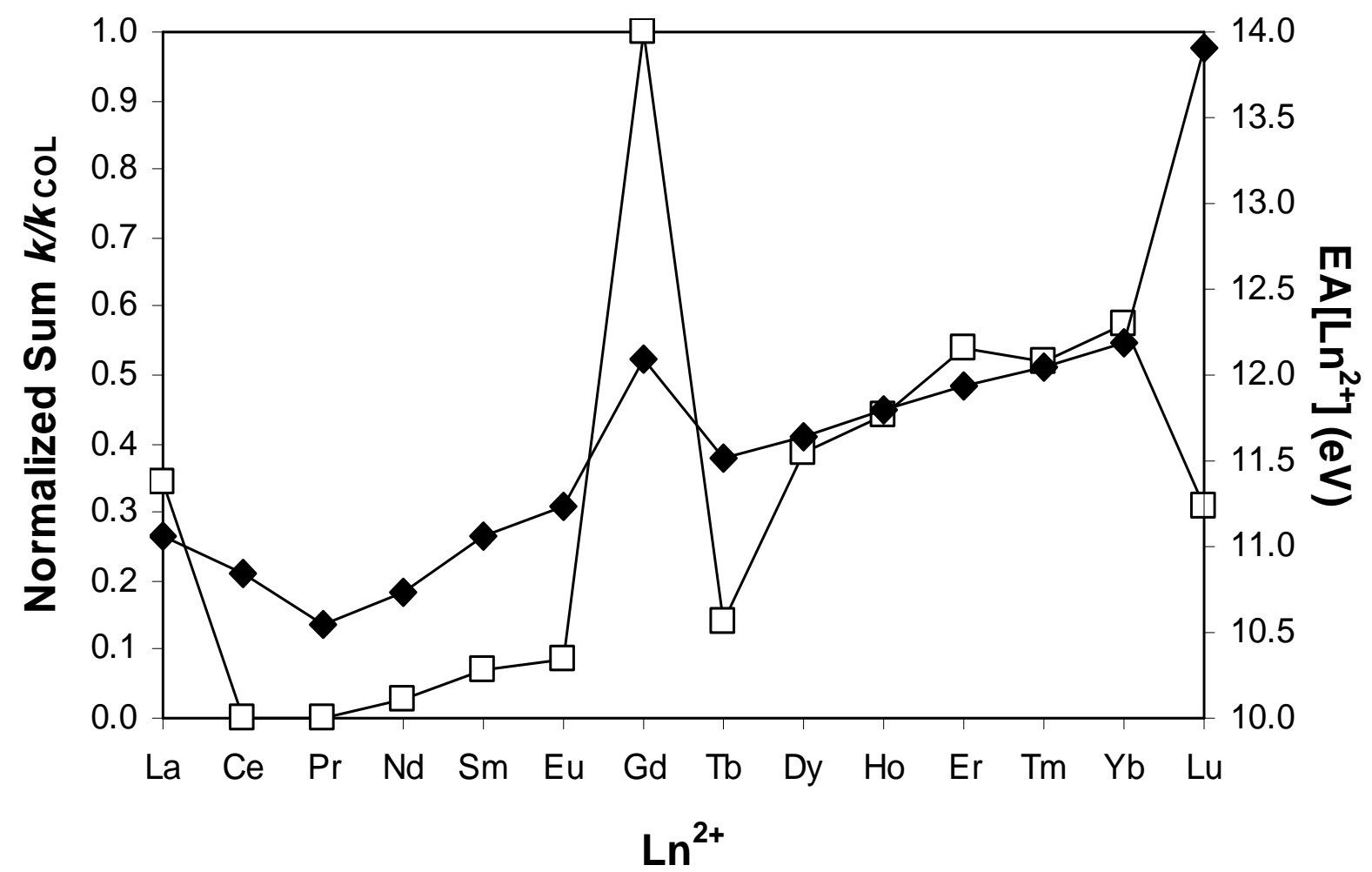

Figure 4. Plot of the normalized sum of the fraction of the $k / k_{\mathrm{COL}}$ corresponding to methide transfer (open squares) and of the $\mathrm{EA}\left[\mathrm{Ln}^{2+}\right]$ for the different lanthanide cations (filled squares). The normalized sums are obtained in an analogous manner as those for electron transfers (Figure 1); for methide transfers, the normalization is relative to $\mathrm{Gd}^{2+}$. 


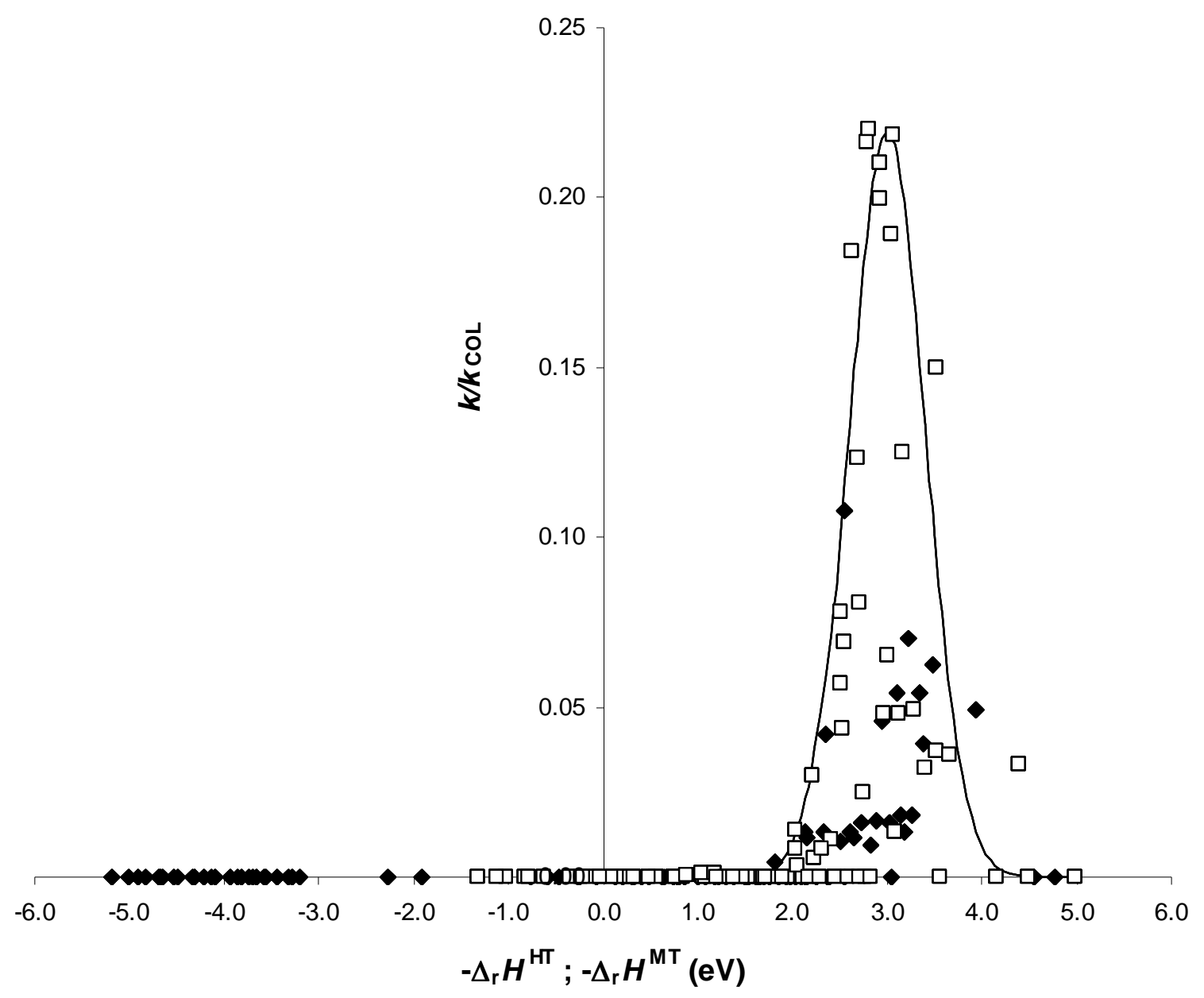

Figure 5. Plot of the individual fractions of the $k / k_{\mathrm{COL}}$ corresponding to hydride transfer (open squares) and methide transfer (filled squares) for all $\mathrm{Ln}^{2+} /$ hydrocarbon pairs, as functions of the exothermicities of the reactions (the Gaussian curve is not a fit to the data points). 


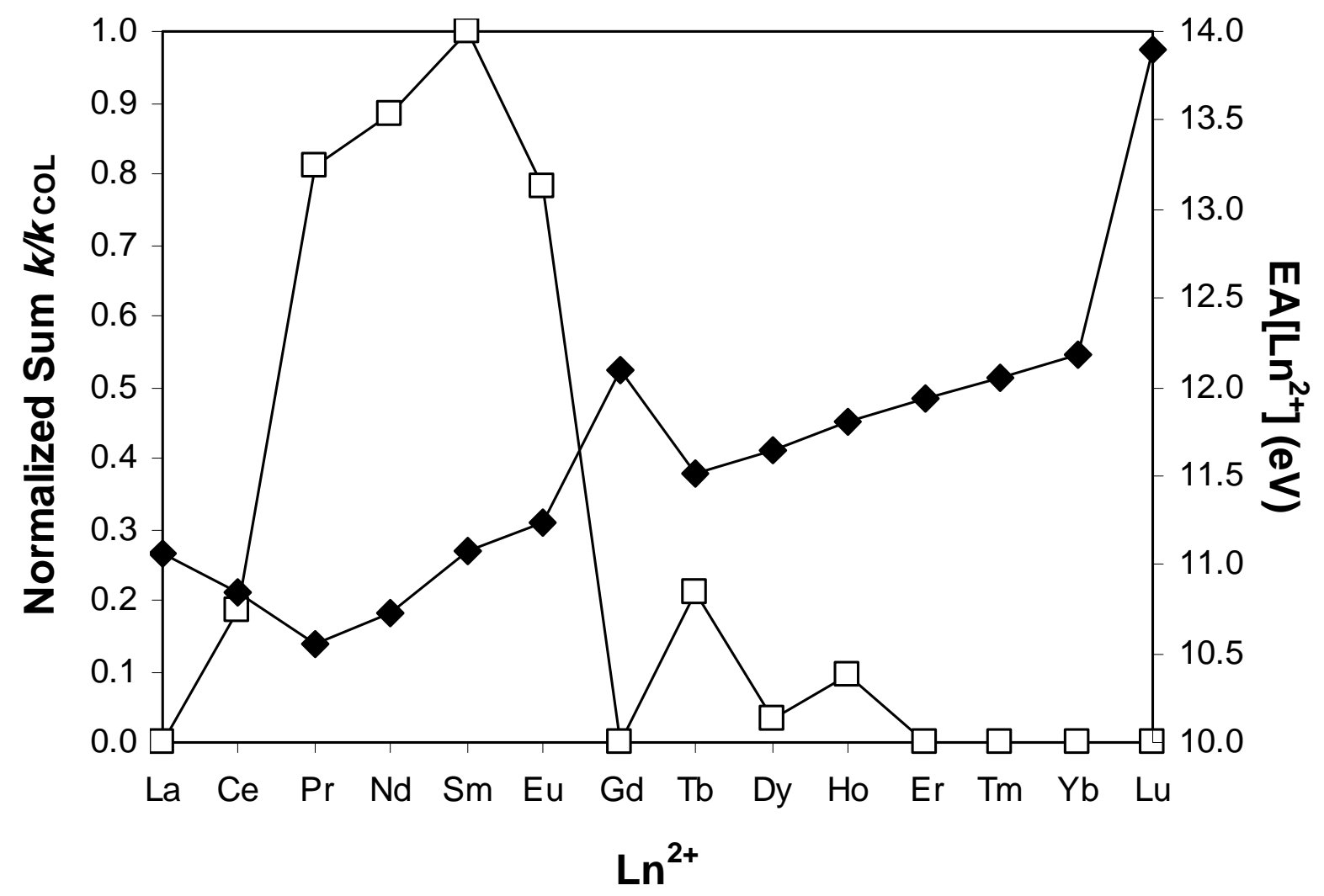

Figure 6. Plot of the normalized sum of the fraction of the $k / k_{\mathrm{COL}}$ corresponding to adduct formation (open squares) and of the $\mathrm{EA}\left[\mathrm{Ln}^{2+}\right]$ for the different lanthanide cations (filled squares). The normalized sums are obtained in an analogous manner as those for electron transfers (Figure 1); for adduct formation, the normalization is relative to that for $\mathrm{Sm}^{2+}$. 


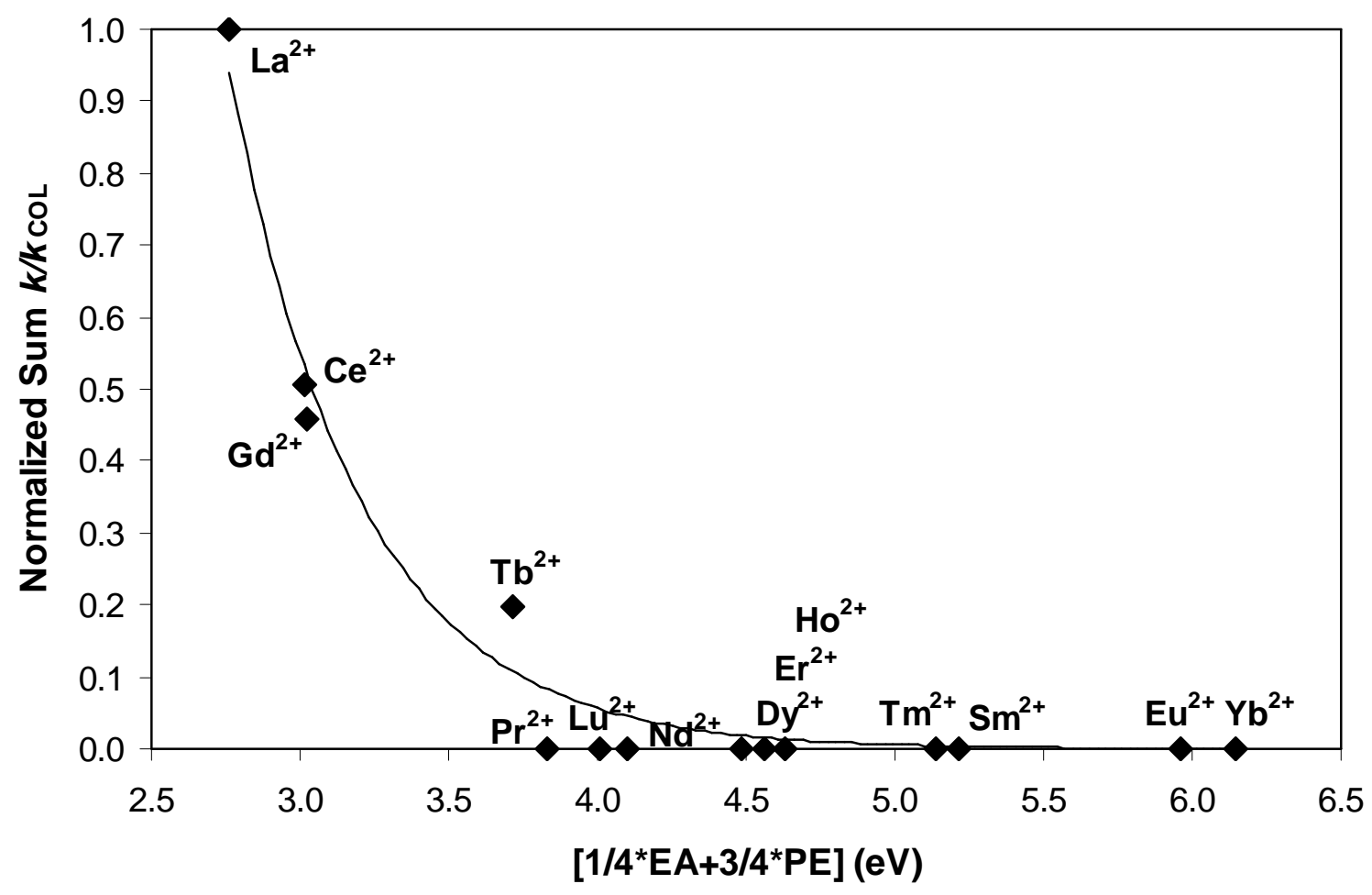

Figure 7. Plot of the $\mathrm{n}$ ormalized sum of the fraction of the $k / k_{\mathrm{COL}}$ corresponding to bond activation and of a weighted combination of the electron affinity (EA) and the ground state to $\mathrm{d}^{1}$ state promotion energies (PEs) of the $\mathrm{Ln}^{2+}$ cations (the line is an approximate exponential fit to the data points). The normalized sums are obtained in an analogous manner as for electron transfers (Figure 1); for activation, the normalization is relative to that for $\mathrm{La}^{2+}$. 


\section{DISCLAIMER}

This document was prepared as an account of work sponsored by the United States Government. While this document is believed to contain correct information, neither the United States Government nor any agency thereof, nor The Regents of the University of California, nor any of their employees, makes any warranty, express or implied, or assumes any legal responsibility for the accuracy, completeness, or usefulness of any information, apparatus, product, or process disclosed, or represents that its use would not infringe privately owned rights. Reference herein to any specific commercial product, process, or service by its trade name, trademark, manufacturer, or otherwise, does not necessarily constitute or imply its endorsement, recommendation, or favoring by the United States Government or any agency thereof, or The Regents of the University of California. The views and opinions of authors expressed herein do not necessarily state or reflect those of the United States Government or any agency thereof or The Regents of the University of California. 